Check for updates

Cite this: RSC Adv., 2019, 9, 40404

Received 16th October 2019

Accepted 30th November 2019

DOI: $10.1039 / c 9 r a 08457 f$

rsc.li/rsc-advances

\section{Advances in nanomaterials as novel elicitors of pharmacologically active plant specialized metabolites: current status and future outlooks}

\author{
Sumaira Anjum, iD *a Iram Anjum, a Christopher Hano iD b and Sidra Kousarc
}

During the last few decades major advances have shed light on nanotechnology. Nanomaterials have been widely used in various fields such as medicine, energy, cosmetics, electronics, biotechnology and pharmaceuticals. Owing to their unique physicochemical characteristics and nanoscale structures, nanoparticles (NPs) have the capacity to enter into plant cells and interact with intracellular organelles and various metabolites. The effects of NPs on plant growth, development, physiology and biochemistry have been reported, but their impact on plant specialized metabolism (aka as secondary metabolism) still remains obscure. In reaction to environmental stress and elicitors, a common response in plants results in the production or activation of different types of specialized metabolites (e.g., alkaloids, terpenoids, phenolics and flavonoids). These plant specialized metabolites (SMs) are important for plant adaptation to an adverse environment, but also a huge number of them are biologically active and used in various commercially-valued products (pharmacy, cosmetic, agriculture, food/feed). Due to their wide array of applications, SMs have attracted much attention to explore and develop new strategies to enhance their production in plants. In this context, NPs emerged as a novel class of effective elicitors to enhance the production of various plant SMs. In recent years, many reports have been published regarding the elicitation of SMs by different types of NPs. However, in order to achieve an enhanced and sustainable production of these SMs, in-depth studies are required to figure out the most suitable NP in terms of type, size and/or effective concentration, along with a more complete understanding about their uptake, translocation, internalization and elicitation mechanisms. Herein, we are presenting a comprehensive and critical account of the plant SMs elicitation capacities of the three main classes of nanomaterials (i.e., metallic NPs (MNPs), metal oxide NPs (MONPs) and carbon related nanomaterials). Their different proposed uptake, translocation and internalization pathways as well as elicitation mechanism along with their possible deleterious effect on plant SMs and/or phytotoxic effects are summarized. We also identified and critically discussed the current research gaps existing in this field and requiring future investigation to further improve the use of these nanomaterials for an efficient production of plant SMs.

\section{Introduction}

In the last few decades, advances in the field of nanotechnology have signaled major achievements and the use of nanomaterials has extensively progressed. Nanomaterials, including nanoparticles (NPs), dendrimers, nanocoatings, nanocomposites, nano-emulsions, nanotubes, fullerenes, nanosheets, and nanoclusters, have delivered what their bulk material had failed to. ${ }^{1,2}$ Today, nanotechnology has infiltrated almost every discipline of science whether in biology, physics, chemistry, material sciences, engineering, biotechnology or

\footnotetext{
${ }^{a}$ Department of Biotechnology, Kinnaird College for Women, Lahore, Pakistan. E-mail: sumaira.anjum@kinnaird.edu.pk; Tel: +92-300-6957038

${ }^{b}$ Laboratoire de Biologie des Ligneux et des Grandes Cultures, INRA USC1328, Université d'Orléans, 28000 Chartres, France

${ }^{c}$ Department of Chemistry, University of Agriculture, Faisalabad, Pakistan
}

medicine. So that, we are currently entering in the Nano Era, a period during which every aspect of life is connected to nanotechnologies. ${ }^{3}$ Nanomaterials are already in use and around us, for examples in textiles, cosmetics, contraptions, appliances, food or environment applications. Extensive research efforts have been made to investigate the potential applications of NPs within human systems, including targeted drug delivery, gene therapy, tissue engineering, cancer therapy, and treatment for infectious and genetic diseases. ${ }^{4,5}$ However, so far, the application of nanotechnology in plant sciences has received comparatively less interest.

Although, nanotechnology, NPs in particular, has been found to solve many of the agriculture-related tailbacks with significant improvement observed in plant growth of plants, nutrient uptake or plant diseases control as compared to the conventional systems. ${ }^{6-8}$ To date, the majority of the studies have been conducted to evaluate the possible beneficial or toxic 


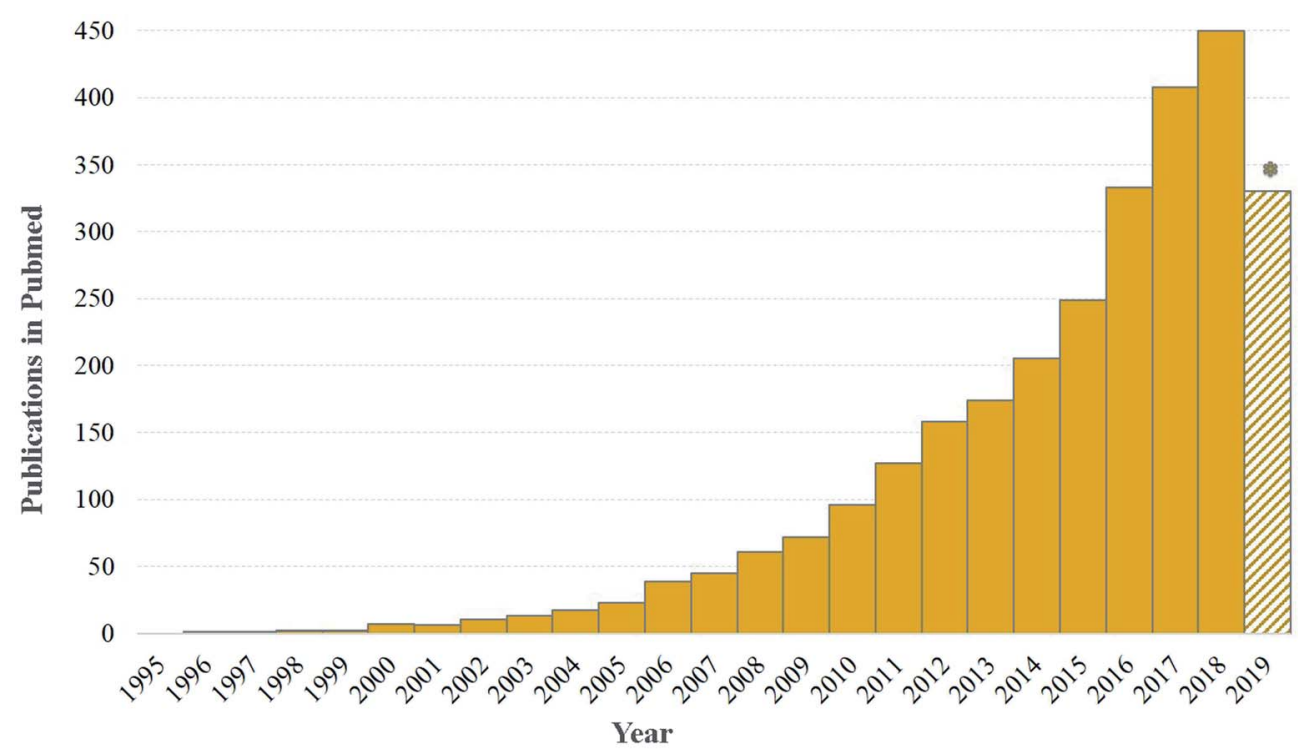

Fig. 1 Evolution of publications numbers on nanotechnology and plant occurring in PubMed during the last 25 years. Note that 2019 was still ongoing (accessed on the 12th of August, 2019).

effects of NPs on plant growth, development, photosynthesis rate and metabolism, in particular on plant specialized metabolism. Activation and reconfiguration of metabolism during plant acclimation and adaptation to adverse environmental conditions usually involved plant specialized metabolism. Stimulation of specialized metabolism to counteract these environmental stresses, led to the production of different classes of plant SMs, ${ }^{9,10}$ including alkaloids, phenylpropanoids (aka polyphenols), terpenoids and sulphur-containing compounds (including glucosinolates) (Fig. 1), known to act as mediators under both biotic and abiotic stress conditions. ${ }^{11}$ Beside their role in plant defense mechanism and plant adaptation, plant SMs are also used as bioactive compounds in human industries as pharmaceuticals for treatment of various diseases or food and cosmetic additives/ingredients. Some examples of bioactive SMs are given in Fig. 2 including antioxidant (quercetin), antimicrobial (rosmarinic acid), antimalarial (quinine and artemisinin), anti-pain (morphine), cardioprotective and anti-diabetes (caffeine), antineurodegenerative (resveratrol), calorie-free sweeteners

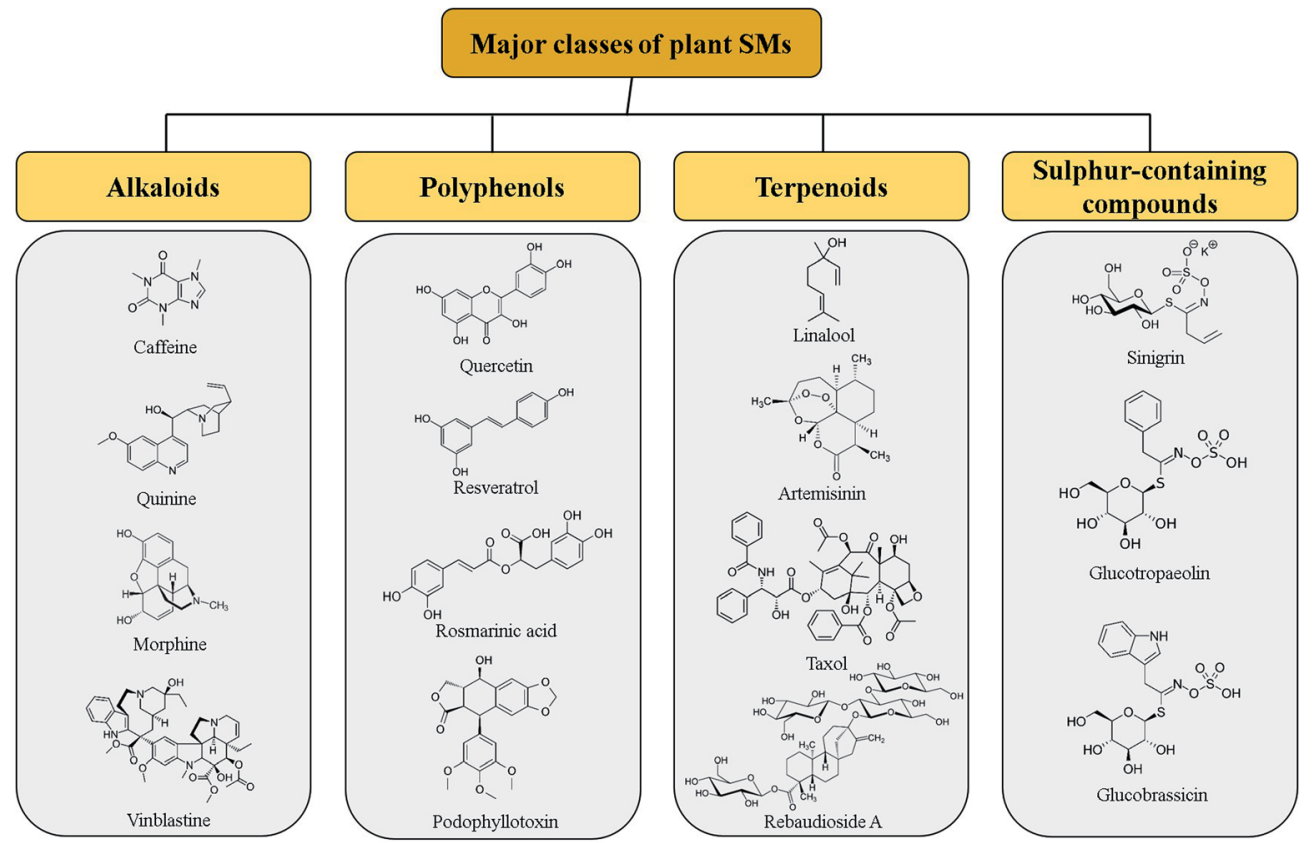

Fig. 2 Pharmacologically important specialized metabolites produced in different plant species along with some peculiar examples of each category. 
(rebaudioside A), natural insect repellent (sinigrin, glucotropaeolin, glucobrassicin), etc. In particular, currently, the $75 \%$ of the pharmaceuticals used for the treatment of cancer originated from plant SMs such as vinblastine, taxol or podophyllotoxin for examples (Fig. 2). ${ }^{12-14}$

The importance of plant SMs in pharmacology and other commercially-valued products, has triggered the development of strategies to enhance their production in plants by exploiting either plant in vitro or in vivo systems. In the recent years, different strategies such as cell line selection, precursor feeding, cell immobilization, biotransformation, metabolic engineering, synthetic biology and elicitation have been designed to improve the production of valuable plant SMs using plant in vitro cultures. Among them, elicitation has emerged as an attractive strategy for enhanced production of pharmaceutically important plant SMs due to its simple implementation and quick responses. ${ }^{15-17}$ To date, different types of biotic and abiotic elicitors have been used for elicitation of plant SMs. Plants respond to these elicitors through the activation of their defense systems, which results in the mobilization of their SMs. In that context, nanotechnology also showed a great potential to elicit plant SMs production, thus providing new tools and new opportunities to develop scalable plant in vitro platforms for the production of valuable SMs. Nanotechnology enters the field of plant science about twenty years ago as shown in Fig. 1. The idea of using nanomaterials as elicitors of plant SMs production is even more recent and has emerged in the forefront during the last 5 years with nearly a hundred publications on the subject of which nearly $60 \%$ were published in the last two years. Currently, different types of NPs have been used as novel and effective elicitors of SMs in in vitro cultures of various plant species. ${ }^{18-20}$ Carbon nanotubes, silver, gold, copper, zinc oxide and titanium dioxide NPs are the most commonly employed types of 'nano-elicitors'. Significant amounts of data on the manipulation of NPs as novel elicitors of plant SMs has been accumulated in the literature in the recent years (Fig. 1). However, a consolidated interpretation or a critical analysis of these published data is not available to the best of our knowledge. This review includes available literature from the last decade. The search terms or keywords, "Nanomaterials", "Elicitors", "Specialized/Secondary metabolism", "Plant specialized/secondary metabolites", "Pharmacologically active compounds" and their combinations were used. Here, we holistically review the available data on the elicitation of specialized metabolites by NPs, along with their exposure, uptake, mechanism of elicitation and possible phytotoxic effects on plants. For this purpose, a systematic review of the literature was conducted by searching information published in original articles, technical reports or conference proceedings in scientific databases such as PubMed, Bentham Science, Direct Science Direct Science, Springer, Google Scholar, BMC, MEDLINE, ScopeMed.

\section{Exposure, uptake and translocation of nanoparticles into plant cells and tissues}

Owing to their unique characteristics, such as small size, high surface to volume ratio, ability to engineer electron exchange and high surface reactive capabilities, NPs can easily enter and interact with several constituents of plant cells and tissues.
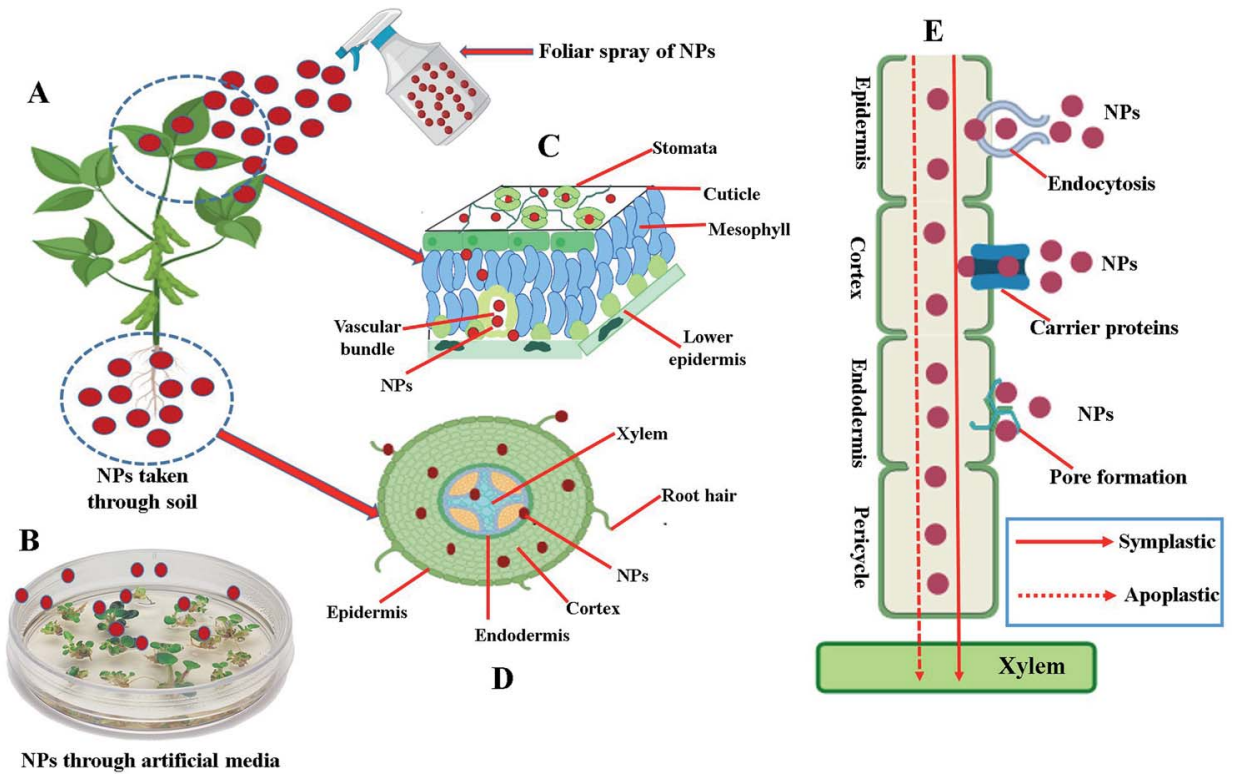

Fig. 3 Schematic illustration of the different routes of uptake, entry and translocation of nanoparticles (NPs) into plant cells and organs. (A) Uptake of NPs by the plant either through the leaf by foliar spray or taken through soil. (B) Uptake of NPs by the seeds/tissues/explant growing on artificial prepared nutrient media. (C) Transverse cross section of leaf showing internalization of NPs taken through leaves by foliar spray. (D) Transverse cross section of root showing internalization of NPs taken through roots of plants. (E) Symplastic or apoplastic translocation/ movement of the NPs through plant cell. 
Uptake of NPs by plants have been detected and confirmed by using various microscopic/spectroscopic techniques such as transmission electron microscopy, scanning electron microscopy, confocal microscopy, energy dispersive spectroscopy, $\mathrm{X}$ ray fluorescence microscopy, atomic force microscopy, light microscopy, two-photon excitation spectroscopy and Raman spectroscopy. ${ }^{\mathbf{1 0 2 1 , 2 2}}$ Plants can uptake NPs by three main ways: (1) through a foliar spray (Fig. 3A and C), (2) through the soil (Fig. 3D), and (3) through the use of artificially prepared nutrient media (Fig. 3B). To enter into the plant cells and tissue, NPs have to cross a first barrier that is the plant cell wall. The plant cell wall pores, with a diameter usually ranging between 5 to $20 \mathrm{~nm}$ in size, can constitute a simple entry way into the plant cells for NPs presenting lesser dimension than the pore diameter. ${ }^{23}$ Some studies also reported the entry of NPs larger than the plant cell wall pore in size either by changing the size of existing plant cell wall pores or by inducting the production of new larger plant cell wall pores. ${ }^{24-26}$ After crossing the plant cell wall, NPs reaches to the cell membrane of plants. From cell membrane, further internalization towards cytosol or other organelles take place either by endocytosis, specific membranebound transporter proteins or through induction of new pores by using ion carrier substances. ${ }^{24,27}$ After internalization, NPs can be transported from one cell to another via apoplastic or symplastic pathways as shown in Fig. 3E. Following entrance, NPs can interact with various organelles and intracellular components of the plant cells, and potentially disturb both primary and specialized metabolism of plants either by generating a stress through the production of reactive oxygen species (ROS) or by other mechanisms discussed in detail in subsequent headings.

To date, NPs uptake, translocation, accumulation and interaction with plant cells and tissue is relatively a new avenue and a few literature data is available regarding their fate in the plant cell. To comprehensively understand the mechanism of elicitation of specialized metabolite by NPs, it would be very important to characterize in-depth their penetration, translocation and interaction modes within plant cells and tissues.

\section{Nanomaterials as elicitors of plant specialized metabolites}

In this review we have categorized the nanomaterials into three main subclasses: (1) metallic NPs, (2) metal oxide NPs and (3) carbon-related nanomaterials, and discussed their elicitation potential of plant SM.

\subsection{Metallic nanoparticles}

Metallic nanoparticles (MNPs) have been largely employed in different plant species, and their impact on mass propagations, genetic manipulation, elimination of microbial content and production of SM have been reported. Owning to their unique properties, different MNPs (Ag, Cu, $\mathrm{Au}, \mathrm{Co}, \mathrm{Zn}$ ) have also been used as elicitors of plant SM in various species (Table 1). The impact of MNPs on SM production was reported to depend on the characteristics of the MNPs (i.e., the concentration used, the exposure time and their size and synthetic origin), but also on the plant culture type. ${ }^{28-30}$ In this review, we have summarized these different parameters that can affect the impact of MNPs on SM production in a number of in vitro cultures of crops and/ or medicinal plant species.

3.1.1. Elicitation potential of silver nanoparticles (AgNPs). Silver nanoparticles (AgNPs) are certainly the most exploited MNPs as elicitors of plant SM in in vitro cultures of various plant species. $^{31-33}$

An effective elicitation of plant SMs of AgNPs have been described for many plant species in diverse production systems. For instance in cell suspension systems, AgNPs $\left(30 \mu \mathrm{g} \mathrm{L}^{-1}\right)$ have been described as an effective elicitor stimulating the production of both lignans $\left(67.23 \mathrm{mg} \mathrm{g}^{-1} \mathrm{DW}\right.$ ) (secoisolariciresinol diglucoside and lariciresinol diglucoside) and neolignans (45.9 $\mathrm{mg} \mathrm{g}^{-1} \mathrm{DW}$ ) (dehydrodiconiferyl alcohol guaiacylglycerol$\beta$-coniferyl alcohol ether glucoside) in cell suspension of Linum usitatissimum. ${ }^{34}$ Cell suspension culture of Capsicum frutescens treated with AgNPs (3.0 $\mathrm{mg} \mathrm{L}^{-1}$ ) accumulated 2-times more capsaicin. ${ }^{19}$ Largely used for its medicinal and cosmetic applications, aloin $(127 \%)$ production was significantly increased in Aloe vera cell suspension treated with AgNPs (at $0.625 \mathrm{mg} \mathrm{L}^{-1}$ ). ${ }^{35}$ Hairy root systems is one of the most operative in vitro platform for production of valuable plant SMs and elicitation experiments by using different MNPs have been reported in hairy root cultures of many plant species..$^{31,36,37}$ In another study, researchers reported a $3.9 \%$ fold increase in production of artemisinin in hairy root culture of Artemisia annua after treatment with AgNPs $\left(900 \mathrm{mg} \mathrm{L}{ }^{-1}\right) .{ }^{37}$ Note that a 2.2 fold increase was also observed in root culture of $A$. annua when treated with cobalt nanoparticles. ${ }^{38}$ Increased production of atropine was observed in hairy root culture of Datura metel after addition of AgNPs (200 mg L $\mathrm{m}^{-1}$ of $50-60 \mathrm{~nm}$ sized) as an elicitor in the culture medium. ${ }^{36}$ Similarly, enhanced production of flavonoids and phenolic compounds were reported in hairy root culture of Cucumis anguria elicited with AgNPs $\left(2.0 \mathrm{mg} \mathrm{L}^{-1}\right) .{ }^{31}$ In vitro grown plants were also considered. Quercetin and glycyrrhizin production was increased in seedlings of Glycyrrhiza glabra following the addition of AgNPs (8-10 $\mathrm{mg} \mathrm{L}^{-1}$ ) to the growth media. Note that in the present case a more complex response was observed with quercetin found in higher level in the aerial parts of the seedlings, while the glycyrrhizin content was found higher in roots. ${ }^{39}$ Similarly, exposure of AgNPs showed both inhibitory and stimulatory effect on SMs production of Calendula officinalis growing under in vitro condition with a strong decrease in carotenoid content, whereas a 2 -fold increase in saponin production was observed. ${ }^{\mathbf{4 0}}$

A particular attention have also to be paid to the AgNPs concentration used. Effect of AgNPs on SM productions is not simple and their impact on plant growth parameters have to be carefully taken into account since growth perturbations or even toxic effects on plants have been reported. A stimulation of taxanes production elicitation in cell suspension culture of hazel cells (Corylus avellana L.) was reported recently. ${ }^{\mathbf{4 1}}$ Hazel cells treated with different concentrations of AgNPs (2.5, 5 and $10 \mathrm{ppm}$ ) during their exponential growth phase and harvested one week after treatment for analysis. A dose dependent effect 

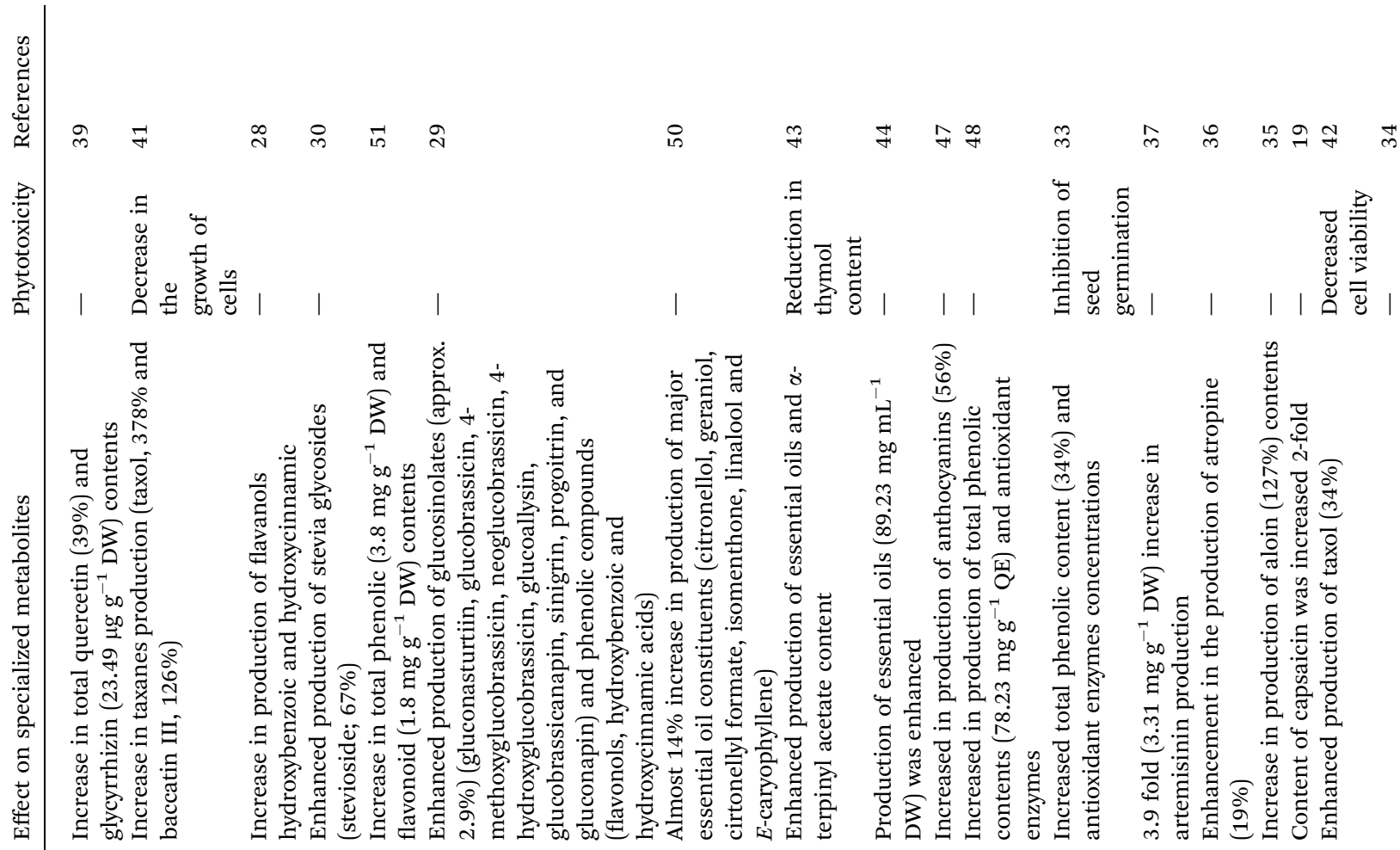

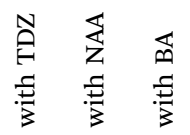

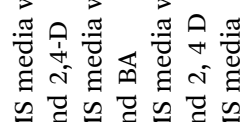

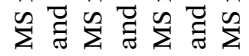
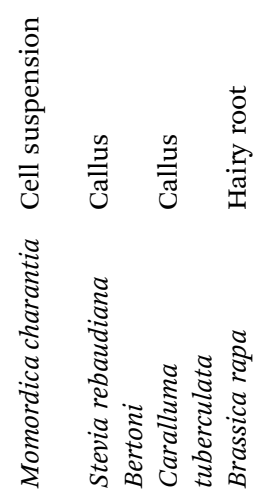

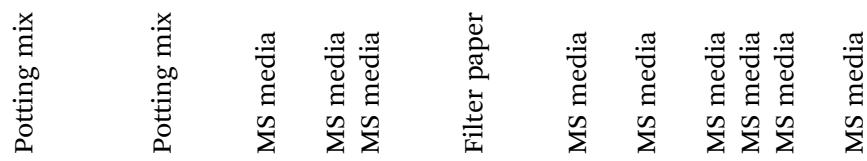

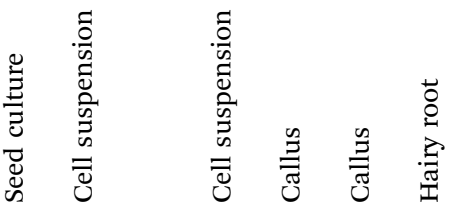

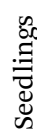

. ఫ్ర

童

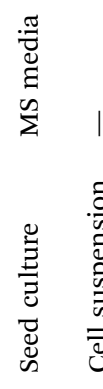

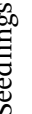

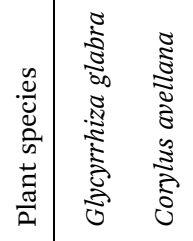

4

है

는

苟

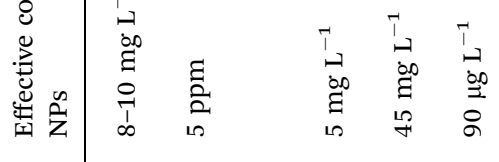

志

है

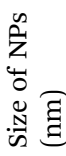

离 
of AgNPs was observed with a strong increased production yields of anticancer taxanes in response to $5 \mathrm{ppm}$ concentration of AgNPs: increased by $378 \%$ for taxol and by $163 \%$ for baccatin III. However, treated cells presented a significant growth reduction. Note that similar positive effect on taxol production in cell suspension culture of the same plant, Corylus avellana, was also described following addition of $5.0 \mathrm{mg} \mathrm{L}^{-1}$ of AgNPs. ${ }^{42}$ The dose dependent effects of AgNPs elicitation was also reported on the production of terpenes in plantlets of Thymus kotschyanus (i.e. increased production of $\alpha$-terpinyl acetate) ${ }^{\mathbf{4 3}}$ and callus culture of Calendula officinalis (i.e. increased production of essential oils). ${ }^{44}$ Chung et al. ${ }^{31}$ investigating the effect of AgNPs on seed germination rate and phenolics production of Ricinus communis reported an ideal concentration of $500 \mathrm{mg} \mathrm{L}^{-1}$ to increase both parameters, whereas a higher concentrations have a negative impact on these parameters. ${ }^{31}$ On the contrary, stimulation of antioxidant phenolic compounds production without severe toxic effects was observed in hydroponically grown Bacopa monnieri treated with AgNPs. ${ }^{45}$ Gupta et al. ${ }^{32}$ reported the stimulatory effect of AgNPs (10-40 $\mathrm{mg} \mathrm{L}^{-1}$ ) on both root and shoot growth along with enhanced production of carotenoid (67\%) in seedlings of Oryza sativa. AgNPs $\left(1 \mu \mathrm{g} \mathrm{mL} \mathrm{m}^{-1}\right)$ elicited in vitro culture of Trigonella foenum graecum showed enhanced production of diosgenin $\left(214.06 \pm 17.07 \mu \mathrm{g} \mathrm{mL}{ }^{-1}\right)$ associated with a significant increase in plant growth. ${ }^{46}$

The size and shape of these MNPs have been shown to affect various growth parameters of plants along with the elicitation of SMs. For instance, spherical $(8 \mathrm{~nm})$, decahedral $(32 \mathrm{~nm})$ and triangular (47 nm)-sized AgNPs were used at the same concentration of $50 \mu \mathrm{M}$ showed contrasting results. ${ }^{47}$ Contrary to decahedral and triangular AgNPs treated-plants, A. thaliana seedlings treated with spherical AgNPs showed enhanced accumulation of anthocyanin without any negative effect on root growth. Similarly, the effect on shoot culture of Vanilla planifolia exposed to different sizes (15-35 nm) of AgNPs, showed that smaller size AgNPs $(18 \mathrm{~nm})$ significantly enhanced production of phenolic compounds (78.23 $\mathrm{mg} \mathrm{g}^{-1} \mathrm{QE}$ ) as compared to larger sized nanoparticles. ${ }^{48}$ A. thaliana plantlets treated with spherical shaped AgNPs $\left(25 \mu \mathrm{g} \mathrm{mL}{ }^{-1}\right)$ ranging in size between 20 to $30 \mathrm{~nm}$ showed enhanced production of anthocyanin, total flavonoid and phenolic contents. ${ }^{49}$

From a mechanistic point of view, most of the studies reported that the generation of reactive oxygen species (ROS) following exposure to MNPs as the central basis for their plant SMs elicitation capacity. ${ }^{29,42,50}$ ROS are known to behave as signaling molecule in the management of plant defense response under both biotic and abiotic stress that could result in the production stimulation of stress-responsive SMs. ${ }^{29}$ reported that the AgNPs exposure to hairy root culture of Brassica rapa resulted in an active generation of ROS (hydrogen peroxide) which in turn activate the plant defense mechanism with an enhanced production of glucosinolates $2.9 \%$ ) (glucoallysin, neoglucobrassicin, glucobrassicanapin, gluconapin, 4-methoxyglucobrassicin, sinigrin, 4-hydroxyglucobrassicin, glucobrassicin, progoitrin and gluconasturtiin), phenolic and flavonoid compounds. Similarly, the generation of ROS after exposure to on exposure of AgNPs (5-35 nm, $40 \mathrm{mg} \mathrm{L}^{-1}$ ) resulted an increased content of essential oil components such as geraniol, citronellyl formate, and E-caryophyllene in Pelargonium graveolens seedlings. ${ }^{\mathbf{5 0}}$

A possible interaction with plant growth regulators have also been proposed. Plant growth regulators are not only essential for plant growth and development but also effect the production of SMs. Plant growth regulators have been employed along with different MNPs to check their combinative effect on elicitation of SMs in various plant species. ${ }^{28,51,52}$ In combination with plant growth regulators (TDZ and 2,4-D), AgNP elicitation of bitter gourd (Momordica charantia) cell culture resulted in an enhanced production of phenolic, hydroxycinnamic and hydroxybenzoic acids, and flavonoids. ${ }^{53}$ Enhanced production of stevia glycosides was observed in callus culture of Stevia rebaudiana Bertoni simultaneously elicited with AgNPs and salicylic acid. ${ }^{52}$ Similar results were reported by Ali et al., ${ }^{51}$ upon treatment of callus culture Caralluma tuberculata with AgNPs along with BA and 2,4 D resulting in an increase productions of total phenolics (3.8 $\left.\mathrm{mg} \mathrm{g}^{-1} \mathrm{DW}\right)$ and flavonoids $\left(1.8 \mathrm{mg} \mathrm{g}^{-1}\right.$ DW). Note that in this later case, an increase in callus proliferation and biomass was also reported.

3.1.2. Elicitation potential of copper nanoparticles (CuNPs). Copper nanoparticles (CuNPs) are used in agricultural science and plant nanotechnology in order to improve growth, yields as well as SMs production. Genady et al. ${ }^{54}$ showed that CuNPs $(5 \mu \mathrm{M})$ are efficient to enhance the production of total phenolic (2-fold) in shoot culture of Verbena bipinnatifida. Another report also suggested the positive effect of CuNPs (50 $\mathrm{mg} \mathrm{L}^{-1}$ ) on the SM production in shoot culture of Solanum lycopersicum, with increased accumulations of lycopene (64.21\%), total phenolic (5.43\%) and flavonoid $(26.21 \%) .{ }^{55}$ Similarly, a significant increase in essential oil contents following CuNPs $\left(0.5 \mathrm{mg} \mathrm{L}^{-1}\right)$ treatment in shoot culture of Mentha longifolia was reported by. ${ }^{56}$ Note that in the same study, the Authors have also reported on a similar effect for cobalt (0.8 $\left.\mathrm{mg} \mathrm{L}^{-1}\right)$ NPs treatment. However, both constructive and destructive effects on plant growth and SMs production of CuNPs treatments have been reported for cucumber plant grown under hydroponic conditions. ${ }^{57}$ The results suggested the activation of defense mechanism following CuNPs treatment and highest metabolic perturbations associated with enhanced production of total phenolic contents were observed in roots in contact with CuNPs.

3.1.3. Elicitation potential of combination of different MNPs/bimetallic nanoparticles. Bimetallic nanoparticles and different combinations of MNPs have also been reported as effective elicitors of SMs production in various plant species. ${ }^{\mathbf{5 8 - 6 0}}$ The effect of $\mathrm{Ag}$ and $\mathrm{Au}$ NPs in combinations $(1: 2,1: 3,2: 1$, and $3: 1$ ) or separately on callus cultures of Prunella vulgaris L., showed that the application of a $1: 3$ ratio of $\mathrm{Ag}$ : Au NPs significantly increased the total flavonoids (4\%) and phenolics (23\%) productions..$^{58}$ More recently, the same authors showed that this $1: 3$ ratio of $\mathrm{Ag}$ : Au NPs was also the most efficient in enhanced production of total phenolic and flavonoid contents in a cell culture system of the same species (i.e. P. vulgaris L.). ${ }^{61}$ $\mathrm{Cu}-\mathrm{Au}$ bimetallic NPs (in a $3: 1$ ratio) were reported as effective 
elicitors for enhanced production of total phenolic (54\%) and flavonoid $(20 \%)$ contents in adventitious root culture of Stevia rebaudiana ${ }^{59,60}$ studying the effect of different ratios $(19: 1,3: 1$, $9: 1$ and $1: 1$ ) of zinc (Zn) and AgNPs on SMs production of Withania somnifera grown under different conditions, proved that the 19:1 ratio was the most effective in enhancing the withanolide content, through the activation of ROS production. A more complex effect was reported for different combinations of Ag and Au NPs used as elicitors of essential oil production in cell suspension culture of Lavandula angustifolia, with a decreased accumulation of low molecular weight components (such as trans-pinocarveol and 1,8-cineole), whereas a concomitant increase in high molecular weight compounds (such as cadalene) was observed. ${ }^{62}$

\subsection{Metal oxide nanoparticles}

The literature provides assorted, and often contradictory results on the plant responses exposed to different metal oxide nanoparticles MONPs. Numerous studies have been carried on the elicitation behaviour of different MONPs in in vitro cultures of various plant species. ${ }^{63-66}$ The most widely used MONPs as elicitors of SMs are copper oxide $(\mathrm{CuO})$, zinc oxide $(\mathrm{ZnO})$, titanium oxide $\left(\mathrm{TiO}_{2}\right)$, cesium oxide $\left(\mathrm{CeO}_{2}\right)$, cadmium oxide $(\mathrm{CdO})$ and aluminum oxide $\left(\mathrm{Al}_{2} \mathrm{O}_{3}\right)$ NPs. Impact of different MONPs on SMs of various plant species is summarized in Table 2. We have also discussed the nonmetallic oxide NPs of silica oxide $\left(\mathrm{SiO}_{2}\right)$ in this subheading.

3.2.1. Elicitation potential of copper oxide nanoparticles (CuONPs). Copper $(\mathrm{Cu})$ is an essential element for plant nutrition, and plays a pivotal role in both primary and specialized metabolism of plants. Numerous studies have been published on the impacts of both $\mathrm{Cu}$ deficiency and excess on these aspects, ${ }^{67,68}$ but only limited information about the effects of CuONPs are available. CuONPs have been proposed as elicitor of valuable bioactive compounds in a bioreactor systems, ${ }^{69}$ but from literature review specific optimizations to the selected plant species and targeted $\mathrm{SM}(\mathrm{s})$ production appear as a critical prerequisite. The efficiency of CuONPs (1 ppm) as elicitors of SMs [total phenolic $\left(27.31 \mathrm{mg} \mathrm{g}^{-1} \mathrm{DW}\right)$, flavonoid $\left(91.11 \mathrm{mg} \mathrm{g}^{-1}\right.$ DW), and tannin (32.02 $\left.\left.\mathrm{mg} \mathrm{g}^{-1} \mathrm{DW}\right)\right]$ production was also assessed by using shoot and tip culture of Withania somnifera. ${ }^{70}$ In the same way, different concentrations of CuONPs $(1,3$ and $5 \mathrm{mg} \mathrm{L}^{-1}$ ) were effectively used to enhanced the production of SMs (phenolics, flavonoids and gymnemic acid) in cell culture of Gymnema sylvestre.$^{64}$ Chung et al. ${ }^{63}$ reported on SMs accumulation but also on the physiological biochemical and transcriptional changes in seedlings of Brassica rapa subjected to CuONPs $(25-55 \mathrm{~nm})$ treatment. CuONPs treatment resulted in a significant increase in anthocyanin (1.1-fold) and phenolic (1.3-fold) accumulations, together with a stimulation of ROS production. However, a negative effect on primary metabolism was observed as evidenced by chlorophyll content and sugar production decreases. This result was confirmed in hairy root culture of the same plant (Brassica rapa) treated with CuONPs showing significantly increased productions of phenolic compounds (hydroxycinnamic acids, flavonols and hydroxybenzoic acid) as described by, ${ }^{63}$ but also of glucosinolates (glucobrassicin, gluconasturtiin, 4-methoxyglucobrassicin, 4-hydroxyglucobrassicin, neoglucobrassicin, glucobrassicanapin, glucoallysin sinigrin, gluconapin and progoitrin) accumulated in high amount in this system. ${ }^{71}$ The effect of CuONPs (1 ppm) for the elicitation of polyphenolic content in shoot culture of chicory (Cichorium intybus L.) investigated by ${ }^{72}$ showed a clear difference in the timing production of the SMs: a significant increase in total phenolic and flavonoid contents was noted after 20 days of nanoparticle treatment, whereas the tannin contents were higher (6-fold) in 10 days-treated shoots and roots of chicory. ${ }^{69}$ studied the effect of CuONPs $\left(5 \mathrm{mg} \mathrm{L}^{-1}\right)$ on seed germination as well as callus induction Trigonella foenum-graecum. Low concentrations of CuONPs resulted in root and shoot elongation but the higher concentrations (4000 $\mathrm{mg} \mathrm{L}^{-1}$ ) suppressed the root development. If there was no obvious effect of CuONPs on seed germination rate, however the used of capped NPs reduced the toxicity. The production of flavonoids and phenolics increased in both roots and shoots.

3.2.2. Elicitation potential of zinc oxide nanoparticles (ZnONPs). Zinc oxide nanoparticles (ZnONPs) have vast array of applications due to their unique optical, catalytic, band gap, and high surface area to volume ratio properties. Their impact on plant SMs was studied in various plant species. ${ }^{18,73-75}$ However, unpredictable results were commonly found in different studies about the interaction of ZnONPs with primary and specialized metabolisms of plants.

The effectiveness of ZnONPs to stimulate plant SMs production was reported in several plant species and culture systems. The total flavonoid contents were increased in callus culture of Echinacea purpurea in response to a $75 \mathrm{mg} \mathrm{L}^{-1}$ treatment with ZnONPs. ${ }^{76}$ Similarly, ZnONPs were found to increase the total phenolic ( $\left.99.1 \mathrm{mg} \mathrm{g}^{-1} \mathrm{FW}\right)$ and anthocyanin $\left(3.28 \mathrm{mg} \mathrm{g}^{-1} \mathrm{FW}\right)$ contents in potato plants when applied at 300 and $500 \mathrm{ppm}$ concentration in media, respectively. ${ }^{77}$ But the response to ZnONPs treatment appears specific to the class of plant SMs considered. Treatment of hairy root culture of Hyoscyamus reticulatus with ZnONPs at different concentrations $(0$, 50,100 and $200 \mathrm{mg} \mathrm{L}^{-1}$ ) revealed a positive effect on the production of both phenolic compounds (3.2-fold) and tropane alkaloids (1.2-fold increase in scopolamine and hyoscyamine). Interestingly, a positive action on the growth rate of the treated hairy root culture was also observed, which is of particular interest considering the action of these phytochemicals used to treat Alzheimer's disease by acting as inhibitors of parasympathetic nervous system..$^{18}$ On the contrary, ${ }^{78}$ using in vitro grown shoots of Stevia rebaudiana reported on both favorable and adverse actions of ZnONPs on diverse classes of SMs. Indeed, their results showed a significant increase in steviol glycosides production ( $\left.88.21 \mathrm{mg} \mathrm{g}^{-1} \mathrm{DW}\right)$ in micro-propagated shoots treated by ZnONPs $\left(1 \mathrm{mg} \mathrm{L^{-1 }}\right)$. However, the total phenolic and flavonoid contents were decreased in the same tissue under the same conditions. In another study, the same authors compared ZnONPs and CuONPs as elicitors of steviol glycosides in callus culture of $S$. rebaudiana. ${ }^{79}$ They reported a higher production of steviol glycosides, phenolics and 


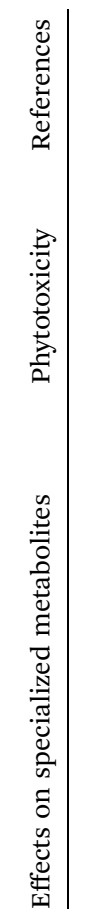

․

$\stackrel{\square}{\circ}$

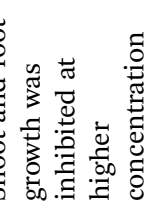

पे

.

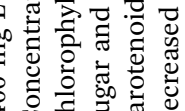

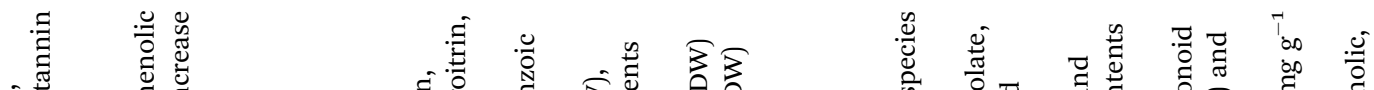

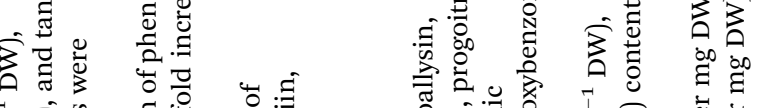

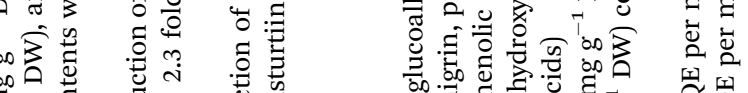

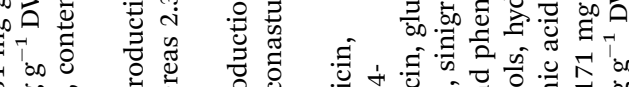

窟

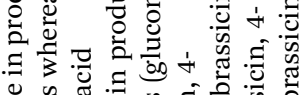

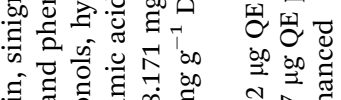




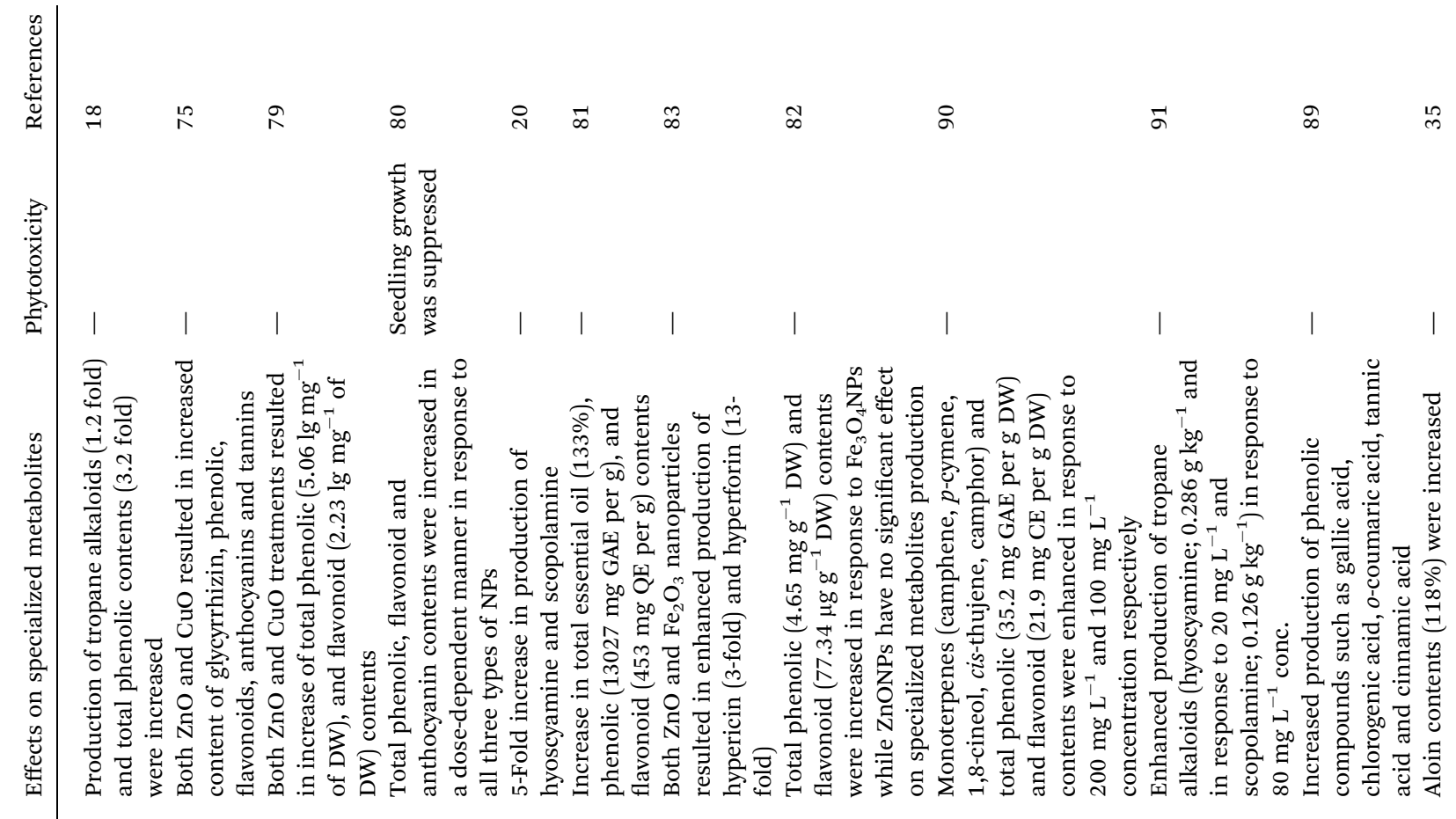

0
0
0
0
0
0
0
0
$\frac{\pi}{20}$
0
0
0
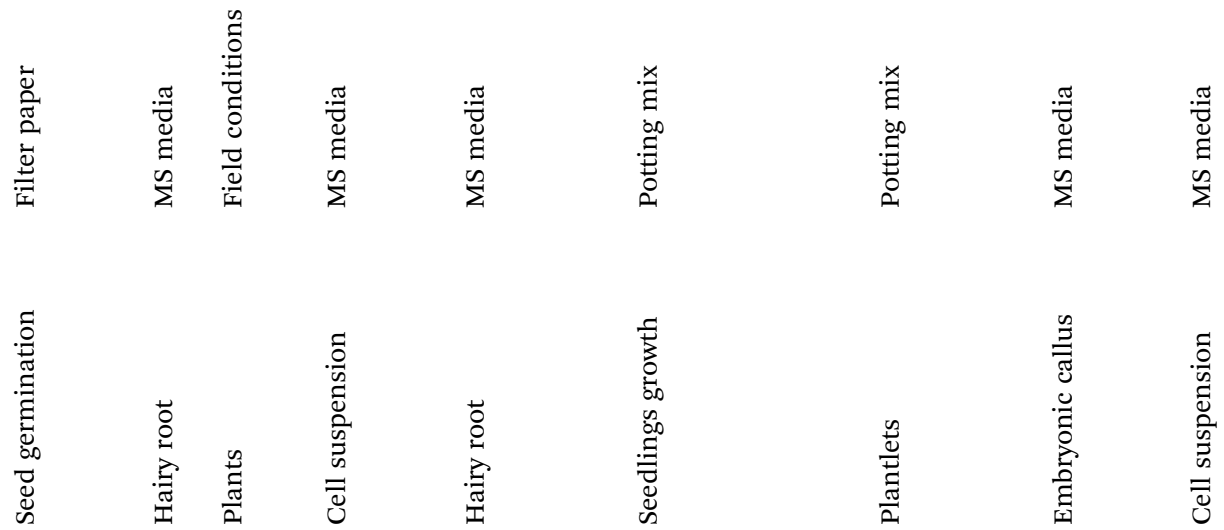

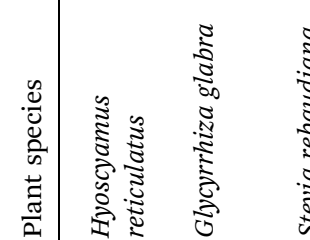
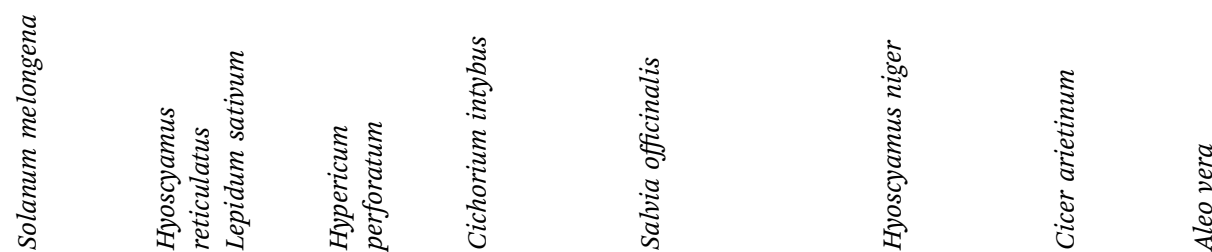

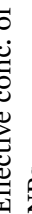<smiles>[Te][Hg]</smiles>

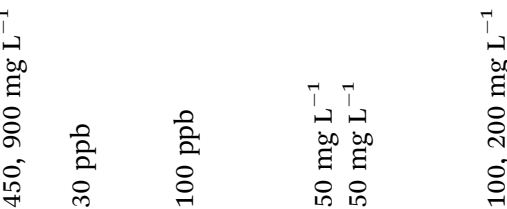

苞

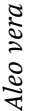

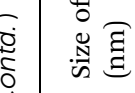

옹ำ

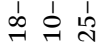

$\stackrel{20}{2}$

$\underset{1}{10}$

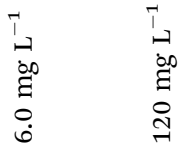

音

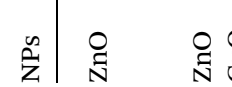

옹 옹

온욣

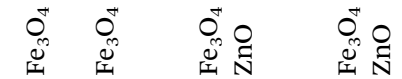

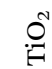

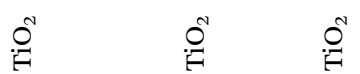


สู ณू \&
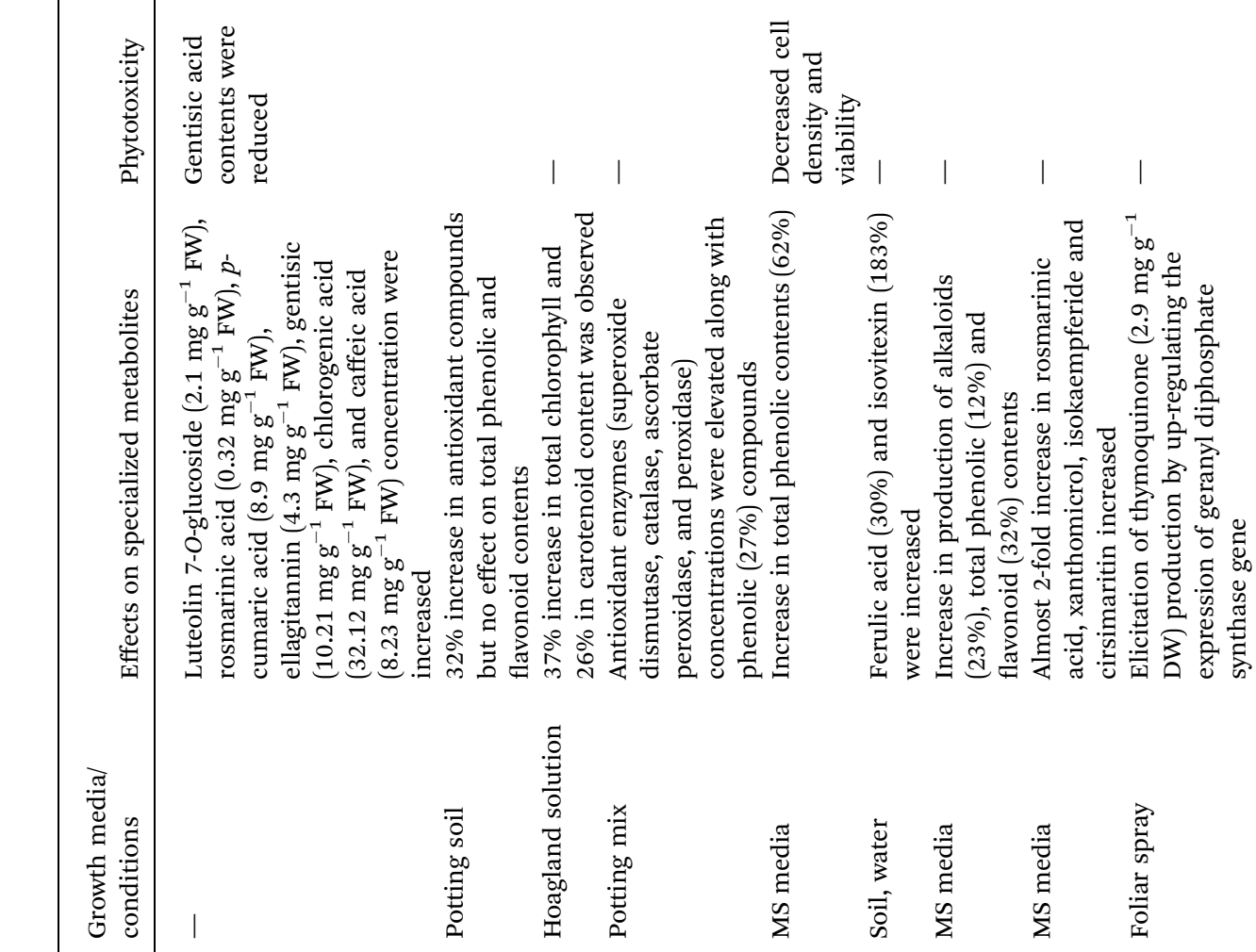

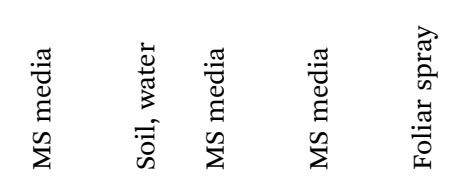

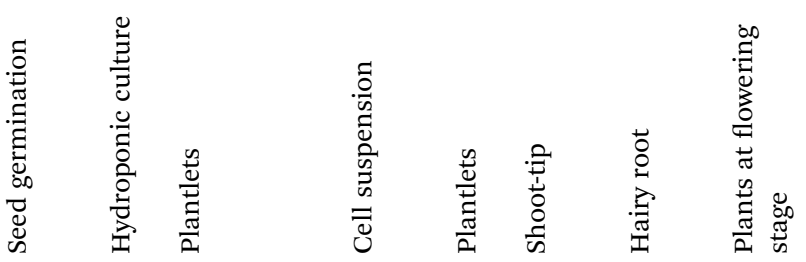

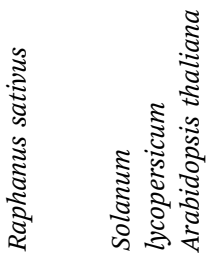

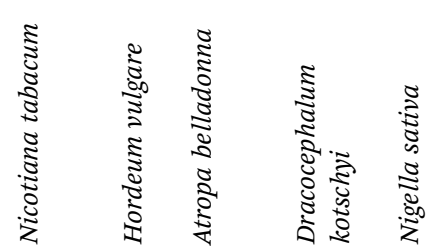

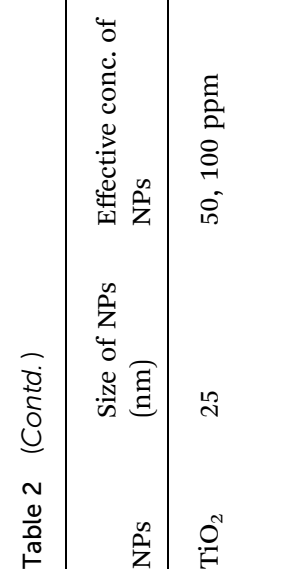

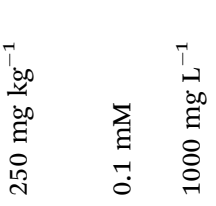

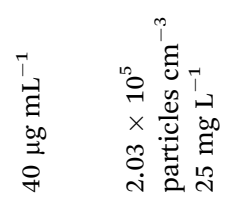

مَ

$\therefore$ 
flavonoids in response to ZnONPs than to CuONPs, certainly as a consequence of the toxic effects observed with CuONPs. But this toxic effect is certainly dependent on the plant species since $^{75}$ reported a significant increase in the accumulation of glycyrrhizin, phenolics, anthocyanins, tannins and flavonoids in 21 days old seedling of G. glabra using a higher concentration of CuONPs $(10 \mu \mathrm{M})$ than ZnONPs $(1 \mu \mathrm{m})$ for the treatment, thus suggesting less toxic effect of CuONPs on this plant species.

Once again, as a first step for the use of these NPs, the applied concentration on the plant culture appears as an important parameter that have to be precisely optimized. For instance, total phenolics, anthocyanins and total flavonoids contents were affected in dose-dependent manner in response to three different types of MONPs (CuONPs, ZnONPs and NiONPs). In this study, different concentrations (100, 250, 500 and $1000 \mathrm{mg} \mathrm{L}^{-1}$ ) of MONPs were used to elicit SMs production in seedlings of Solanum melongena. Best results on SMs production were obtained with CuONPs at a concentration level of $500 \mathrm{mg} \mathrm{L}^{-1}$, but some negative effects where observed on plant growth as well as viability, mainly due to the generation of high levels of ROS in response to NPs. If the toxic effects are subsided, these MONPs, CuONPs in particular, could be a source of useful specialized metabolites. ${ }^{80}$ One possibility to cope with this toxic effect, could be the association with humic acid as suggested by. ${ }^{73}$ These Authors reported on the impact of ZnONPs along with humic acid on Lilium ledebourii plantlets. Once again a ZnONPs dose dependent response for the production of SMs was observed, with maximum production of phenolic acids $\left(75 \mathrm{mg} \mathrm{L}^{-1}\right)$ and anthocyanins $\left(100 \mathrm{mg} \mathrm{L}^{-1}\right)$ obtained at $75 \mathrm{mg} \mathrm{L}^{-1}$ of ZnONPs, whereas highest flavonoid content $\left(25 \mathrm{mg} \mathrm{L}^{-1}\right)$ were obtained with $25 \mathrm{mg} \mathrm{L}^{-1}$ of ZnONPs. Interestingly, explants treated with humic acid gave attractive results on plant growth parameters such as highest root length, leaf length, and chlorophyll contents. It was suggested that both the humic acid and ZnONPs might be used as good elicitors and can probably stimulate the synthesis of SMs. ${ }^{73}$ Future studies using combination of ZnONPs along with humic acid treatment to evaluate if this later could be a solution to subside the toxic effects of ZnONPs would be of particular interest.

3.2.3. Elicitation potential of iron oxide nanoparticles $\left(\mathbf{F e}_{3} \mathbf{O}_{4} \mathbf{N P s}\right)$. Their simple and cost-effective synthesis makes iron oxide nanoparticles $\left(\mathrm{Fe}_{3} \mathrm{O}_{4} \mathrm{NPs}\right)$ readily available for various applications in various fields of science including their potential use as elicitors of plant SMs production..$^{20,81-83}$ For instance, $\mathrm{Fe}_{3} \mathrm{O}_{4}$ NPs can be more effective than other MONPs such as ZnONPs to elicit SMs production, as suggested with hairy root culture of Cichorium intybus. Indeed, results showed that contrary to ZnONPs, $\mathrm{Fe}_{2} \mathrm{O}_{3}$ NPs application proved to be proficient elicitor treatment to enhance both growth and production of phenolic (4.65 $\left.\mathrm{mg} \mathrm{g}^{-1} \mathrm{DW}\right)$ and flavonoid $\left(77.34 \mu \mathrm{g} \mathrm{g}^{-1} \mathrm{DW}\right)$ compounds in hairy root culture of $C$. intybus. ${ }^{82}$ Another interesting example of the use of $\mathrm{Fe}_{3} \mathrm{O}_{4} \mathrm{NPs}$ was obtained with Hypericum perforatum. This plant is one of top selling product in industrial based countries for medicinal uses, due to its accumulation of particular SMs: hypericin (3-fold) and hyperforin (13-fold). H. perforatum in vitro cultures have attracted an active search, including the evaluation of a large number of different elicitors, in order to enhance their production at acceptable levels for commercial applications. ${ }^{\mathbf{8 4 , 8 5}}$ Interestingly, in a study was conducted with cell suspension cultures of $H$. perforatum, after testing several concentrations, $\mathrm{Fe}_{3} \mathrm{O}_{4} \mathrm{NPs}(100 \mathrm{ppb})$ showed their ability to specifically increase the production of hyperforin as compared to the hypericin. ${ }^{83}$ These results suggested, following optimization, the possibility of directing a metabolic pathway toward the synthesis of the desired compound. Another study evidenced the synergistic effect of foliar application of $\mathrm{Fe}_{3} \mathrm{O}_{4} \mathrm{NPS}$ on Cress (Lepidum sativum L.) plants resulting from gamma-irradiated seeds. ${ }^{81} \mathrm{Fe}_{3} \mathrm{O}_{4} \mathrm{NPs}$ (30 ppb) significantly increased the production of both total phenolic (13027 mg GAE per g), and flavonoid (453 mg QE per g) contents, and a synergistic effect with a prior gamma ray treatment of the seeds was noted. Moreover, repeated elicitation with $\mathrm{Fe}_{3} \mathrm{O}_{4} \mathrm{NPs}$ was able to further potentiate the production of these SMs. ${ }^{81}$ Nevertheless, although all these results are very promising, a prior optimization of $\mathrm{Fe}_{3} \mathrm{O}_{4}$ NPs concentrations and treatment duration to applied are nevertheless necessary to avoid undesirable toxic effects, as indicated in the latest study conducted on hairy root culture of Hyoscyamus reticulatus. Applied at different concentrations (0, 450, 900, 1800, and $3600 \mathrm{mg} \mathrm{L}^{-1}$ ) and for different exposure times (24, 48, and $72 \mathrm{~h}$ ), results showed a concentration- and time-dependent activation of the tropane alkaloids (5-fold; hyoscyamine and scopolamine) biosynthesis, in 450 and $900 \mathrm{mg} \mathrm{\textrm {L } ^ { - 1 }}$ of $\mathrm{Fe}_{3} \mathrm{O}_{4} \mathrm{NPs}$-treated cultures after $24 \mathrm{~h}$ and $48 \mathrm{~h}$ of exposure time, respectively. However, the prolonged exposure time (i.e. $96 \mathrm{~h}$ ) led to decrease in tropane alkaloids (2-fold) production and suggested potential toxic effects of $\mathrm{Fe}_{3} \mathrm{O}_{4} \mathrm{NPs}^{20}$

3.2.4. Elicitation potential of titanium dioxide nanoparticles $\left(\mathrm{TiO}_{2} \mathbf{N P s}\right)$. Titanium dioxide nanoparticles $\left(\mathrm{TiO}_{2} \mathrm{NPs}\right)$ are one of the most widely released nanoparticles in the environment, especially because of their wide use as a UV filter in sunscreens. Therefore, plants are more prone to $\mathrm{TiO}_{2} \mathrm{NPs}$ they can directly uptake from environment. ${ }^{86}$ The most recent studies suggested that the physiological effects of $\mathrm{TiO}_{2} \mathrm{NPs}$ on plants are mainly caused by ionic $\mathrm{Ti}^{87,88}$ Various research groups have also investigated the elicitation potential of $\mathrm{TiO}_{2}$ NPs on plant SMs production using both in vivo and in vitro systems. ${ }^{89-91}$ Using in vitro systems, aloin (118\%) content was increased in cell suspension culture of Aloe vera when treated with $\mathrm{TiO}_{2} \mathrm{NPs}^{35}$ Similarly, the phenolic and flavonoid contents in callus culture of Cicer arietinum were increased when exposed to different concentrations of $\mathrm{TiO}_{2} \mathrm{NPs}^{89}$ The authors reported a significant dose-dependent increase in the production of gallic acid, $o$-coumaric acid and tannic acid in response to $6 \mathrm{mg} \mathrm{L}^{-1} \mathrm{TiO}_{2} \mathrm{NPs}$, whereas the chlorogenic acid and $t$-cinnamic acid at $4.5 \mathrm{mg} \mathrm{L}^{-1} \mathrm{TiO}_{2} \mathrm{NPs}$. Using in vivo systems, application of different concentrations $\left(0,10,50,100,200\right.$ and $\left.1000 \mathrm{mg} \mathrm{L}^{-1}\right)$ of $\mathrm{TiO}_{2}$ NPs (10-15 nm size) on seedlings of Salvia officinalis aslo evidenced a dose-dependent response with highest accumulation of total phenolic content $\left(35.2 \mathrm{mg} \mathrm{g}^{-1} \mathrm{DW}\right)$ at a $200 \mathrm{mg} \mathrm{L}^{-1}$ dose, while the highest total flavonoids content $\left(21.9 \mathrm{mg} \mathrm{g}^{-1}\right.$ DW) at $100 \mathrm{mg} \mathrm{L}^{-1}$ treatment of $\mathrm{TiO}_{2}$ NPs was observed. Moreover, a significant increase in essential oil content at a dose of $200 \mathrm{mg} \mathrm{L}{ }^{-1} \mathrm{TiO}_{2}$ NPs was also noted..$^{90} \mathrm{~A}$ study conducted on 
Hyoscyamus niger, compared the impact of $\mathrm{TiO}_{2} \mathrm{NPs} v s$. bulk titanium, showed a significant biomass (dry weight) improvement for plants treated with $40 \mathrm{mg} \mathrm{L}^{-1}$ of $\mathrm{TiO}_{2} \mathrm{NPs}(10-15 \mathrm{~nm}$ size), whereas bulk titanium was ineffective on this growth parameter. On the SMs production, highest content of hyoscyamine $\left(0.286 \mathrm{~g} \mathrm{~kg}^{-1}\right)$ was observed with a concentration of $80 \mathrm{mg} \mathrm{L}{ }^{-1} \mathrm{TiO}_{2} \mathrm{NPs}$, while highest scopolamine content (126 g $\mathrm{kg}^{-1}$ ) was reported at a lower concentration of $\mathrm{TiO}_{2} \mathrm{NPs}$ $\left(20 \mathrm{mg} \mathrm{L}{ }^{-1}\right) .{ }^{91}$ In a recent study, the complex effect of drought stress and different concentrations $\mathrm{TiO}_{2} \mathrm{NPs}(0,10$ and $40 \mathrm{ppm})$ on dragonhead Dracocephalum moldavica was reported by ${ }^{\mathbf{2}}$ in a factorial experiment. Under normal irrigation, foliar application of $\mathrm{TiO}_{2}$ NPs at $10 \mathrm{ppm}$ improved plant biomass as well as essential oils production. Furthermore, the Authors showed that drought stress-induced oxidative damages can be overpassed by foliar application of $\mathrm{TiO}_{2} \mathrm{NPs}$ at appropriate concentrations. This result is of particular interest in the context of increasing temperatures due to climate change and should deserve additional research considerations.

3.2.5. Elicitation potential of cerium oxide nanoparticles $\left(\mathrm{CeO}_{2} \mathrm{NPs}\right)$. Cerium oxide nanoparticles $\left(\mathrm{CeO}_{2} \mathrm{NPs}\right)$ have been found to be very stable with limited dissolution in soil, however, root exudates could enhance the solubility of $\mathrm{CeO}_{2} \mathrm{NPs}$, leading to significant accumulation of $\mathrm{Ce}$ in plant tissues. ${ }^{\mathbf{9 3}, 94}$ Cerium (Ce) is a rare earth elements (REEs), and although it is not essential for plants, it have been reported to stimulate growth and other physiological processes. ${ }^{95}$ There are also many reports are present that demonstrate the potential impact of $\mathrm{CeO}_{2} \mathrm{NPs}$ on plant primary metabolism, but a few literature on their impact(s) on plant SMs production is so far exiting. ${ }^{95-97}$ Hydroponic culture of Solanum lycopersicum elicited with $\mathrm{CeO}_{2} \mathrm{NPs}$ (0.1 Mm, $33.05 \mathrm{~nm}$ size) showed a significant increase in their carotenoid contents (26\%). ${ }^{96}$ Comparatively, both applications of $\mathrm{CeO}_{2} \mathrm{NPs}\left(1000 \mathrm{mg} \mathrm{L}^{-1}\right)$ and indium oxide NPs $\left(\mathrm{In}_{2} \mathrm{O}_{3} \mathrm{NPs}\right.$, $250 \mathrm{mg} \mathrm{L}^{-1}$ ) induced an oxidative stress associated with an increase in production of phenolic compounds (27\%) in plantlets of $A$. thaliana. ${ }^{97}$ On the contrary, application of $\mathrm{CeO}_{2}$ NPs has been shown to improve the radical scavenging potency upto $32 \%$ of radish (Raphanus sativus) seedlings but have no effect on the production of phenolic and flavonoid compounds. ${ }^{95}$

3.2.6. Elicitation potential of aluminum $\left(\mathrm{Al}_{2} \mathrm{O}_{3} \mathrm{NPs}\right)$, manganese ( $\left.\mathrm{Mn}_{2} \mathrm{O}_{3} \mathrm{NPs}\right)$ and cadmium (CdONPs) oxide nanoparticles. Aluminium oxide $\left(\mathrm{Al}_{2} \mathrm{O}_{3}\right)$, cadmium oxide $(\mathrm{CdO})$ and manganese dioxide $\left(\mathrm{Mn}_{2} \mathrm{O}_{3}\right)$ nanoparticles are to date the least exploited nanomaterials as elicitors of plant SMs. Application of $\mathrm{Al}_{2} \mathrm{O}_{3}$ NPs on tobacco BY-2 cell suspension culture led to substantial increase in phenolic content (62\%) in a dosedependent way. A stimulation of biomass production (fresh weight) was also observed at $100 \mu \mathrm{g} \mathrm{mL}{ }^{-1} \mathrm{Al}_{2} \mathrm{O}_{3} \mathrm{NPs} .{ }^{98}$ A study with Hordeum vulgare (barley) plants exposed to CdONPs (ranging from 7-60 $\mathrm{nm}$ in size and $2.03 \times 10^{5}$ particles per $\mathrm{cm}^{3}$ concentration) reported an increased production of isovitexin (183\%) and ferulic acid (30\%) and also suggested a rapid penetration of CdONPs through soil along with water into the plants as compared to foliar spray. ${ }^{99} \mathrm{~A}$ very little is known about the interaction of plants with $\mathrm{Mn}_{2} \mathrm{O}_{3}$ NPs. A study was conducted to explore the prospective effects of $\mathrm{Mn}_{2} \mathrm{O}_{3} \mathrm{NPs}$ on morphology, physiology and specialized metabolism in shoot tip cultures of Atropa belladonna. Results showed that, at appropriate dosage $\left(25 \mathrm{mg} \mathrm{L^{-1 }}\right), \mathrm{Mn}_{2} \mathrm{O}_{3} \mathrm{NPs}$ were found to stimulate both plant growth and SMs production (23\% increase in alkaloids, $12 \%$ in total phenolic and $32 \%$ in flavonoid contents). From this study, $\mathrm{Mn}_{2} \mathrm{O}_{3} \mathrm{NPs}$ would be further considered as a novel extracellular elicitor of SMs in in vitro cultures of medicinally or biotechnologically important plant species. ${ }^{100}$

3.2.7. Elicitation potential of silicon dioxide nanoparticles ( $\mathrm{SiO}_{2} \mathbf{N P s}$ ). To date, only two studies have been carried out to investigate the effect of silicon dioxide nanoparticles $\left(\mathrm{SiO}_{2} \mathrm{NPs}\right)$ on specialized metabolism of plants. The first study, reported a 2-fold increase in biosynthesis of rosmarinic acid, xanthomicrol, isokaempferide and cirsimaritin in the hairy root culture of Dracocephalum kotschyi, after 48 h of exposure to $\mathrm{SiO}_{2} \mathrm{NPs}(100$ $\mathrm{nm}) .{ }^{101}$ The second report, in early flowering plants of Nigella sativa $\mathrm{TiO}_{2} \mathrm{NPs}$ were found to be more effective than $\mathrm{SiO}_{2} \mathrm{NPs}_{\text {in }}$ stimulating the production of thymoquinone. ${ }^{102}$

\subsection{Carbon-related nanomaterials as elicitor of specialized metabolites of plants}

Beside MNPs and MONPs, the other nanomaterials include semiconductor quantum dots, polymeric nanoparticles, dendrimers and carbon based nanomaterials. Among these other nanomaterials, carbon-based nanomaterials were widely used in agriculture biotechnology to check their effects on primary and specialized metabolisms of various plant species. ${ }^{74,103,104}$ Carbon based nanomaterials include, single-walled carbon nanotubes (SWCNTs), multi-walled carbon nanotubes (MWCNTs), and derivatives of fullerene (Buckminsterfullerene or Buckyball). Literature data showed that SWCNTs and MWCNTs affect the physiology, growth and metabolism of plants in diverse ways. ${ }^{\mathbf{1 0 5 , 1 0 6}}$ Besides these, different studies suggested that the carbon nanotubes and fullerenes could potentially modify the expression level of genes involved in plant specialized metabolism and therefore can act as potent elicitors of various commercially important SMs. ${ }^{107-109}$ Table 3 summarize the elicitation potentials in various plant species of carbon based nanomaterials as well as of chitosan-NPs also discussed in the present section.

3.3.1. Elicitation potential of carbon nanotubes. Concerning SWCNTs, ${ }^{107}$ evaluating the impact of different concentrations $\left(125,150,250\right.$ and $\left.500 \mathrm{mg} \mathrm{L}^{-1}\right)$ on whole plant culture of Tanacetum parthenium showed a favorable effect on the accumulation of parthenolide contents (2.5-fold) in shoot treated at a $500 \mathrm{mg} \mathrm{L}^{-1}$ SWCNTs concentration level. ${ }^{107}$ On in vitro cultures, a significant increase in total phenolic, flavonoid and tannin contents in shoot culture of Simmondsia chinensis treated with SWCNTs $\left(0.002 \mathrm{~g} \mathrm{~L}^{-1}\right)$ was reported. ${ }^{108}$

The inductive effect of MWCNTs on SMs production was also reported on in vitro callus cultures of Satureja khuzestanica with an optimal concentration of $100 \mu \mathrm{g} \mathrm{mL} \mathrm{m}^{-1}$ MWCNTs, improving both biomass and accumulation of total phenolic (12\%), flavonoids (3\%), rosmarinic acid (12.32 $\left.\mathrm{mg} \mathrm{g}^{-1} \mathrm{DW}\right)$ and caffeic acid (9.2 $\mathrm{mg} \mathrm{g}^{-1}$ DW) contents. ${ }^{109}$ 
Kole et al. ${ }^{110}$ have studied the effect of fullerenes (10.8 Mm) on seed germination of bitter melon ( $M$. charantia) and showed a significant increase in seedling growth rate and in anticancer (cucurbitacin-B, $74 \%$ and lycopene, 82\%) and antidiabetic (charantin, 20\% and insulin, 90\%) compounds accumulation after fullerenes exposure.

3.3.2. Elicitation potential of chitosan nanoparticles. Chitosan is widely used for agriculture and biomedicine purposes. It possess attractive unique properties like its non-toxicity and biodegradability. To date, only one report is available on the elicitation behavior of chitosan-NPs (40-180 nm) used as potent elicitors of gallic acid, epicatechin, epigallocatechin, epigallocatechin-gallate and caffeine accumulation in tea (Camellia sinensis) plants growing under hydroponic conditions. ${ }^{111}$

\section{Postulated mechanism of elicitation of specialized metabolites by nanomaterials}

Although a number of reports suggested various signaling pathways to explain the modulation capacity of nanomaterials on the production of plant SMs, to date the precise mechanism still remains elusive. ${ }^{\mathbf{1 0 5 1 , 8 4 , 1 0 9}}$ Probably, because elicitation mechanisms are very complex, and could involve thousands of mediators from multiple signaling pathways and their crosstalk. Additionally, all these events fluctuate depending on the origin, specificity, exposure type, time and concentration of elicitors along with the plant dependent parameter such as the plant species developmental stage, cellular cycle, type of tissue, nutritional conditions, elicitor uptake by media/soil/aerial, physiochemical environment and so on. It is, therefore, very challenging to propose a universal model for the elicitation mechanism of plant SMs production triggered by nanomaterials. We anticipate that the initial responses of plants to NPs might include calcium ion $\left(\mathrm{Ca}^{2+}\right)$ and $\mathrm{Ca}^{2+}$ flux movements and ROS produced by oxidative burst as important second messengers leading to the (up) regulation/phosphorylation of mitogen-activated protein kinase (MAPK) cascades regulation the transcriptional levels of master regulators of plant SMs biosynthesis, which are a common feature observed for many abiotic elicitors. Fig. 4 illustrate a hypothesized mechanism for the elicitation of plant SMs by nanomaterials summarizing the view of different researchers. ${ }^{\mathbf{1 0 1 1}, \mathbf{1 1 2}}$ NPs mostly act as elicitation signal that could interact with elicitor binding sites and/or receptors present at the surface of the plant cell membrane. Upon recognition, interaction and/or binding phase(s), a cascade of events are activated as mentioned above. The initial plant response to NPs is most probably involve an active exchange of ions, for instance $\mathrm{Na}^{+} / \mathrm{K}^{+} / \mathrm{Cl}^{-}$effluxes and $\mathrm{Ca}^{2+} / \mathrm{H}^{+}$ influxes through plasma membrane into the cytosol. $\mathrm{Ca}^{2+}$ influx is considered as the most important event because of its diverse involvement in various physiological and cellular pathways, ${ }^{\mathbf{1 1 3}}$ and can probably play a pivotal role in the first steps of this elicitation mechanism. ROS generation in response to NPs is another important and widely proposed event that can be 


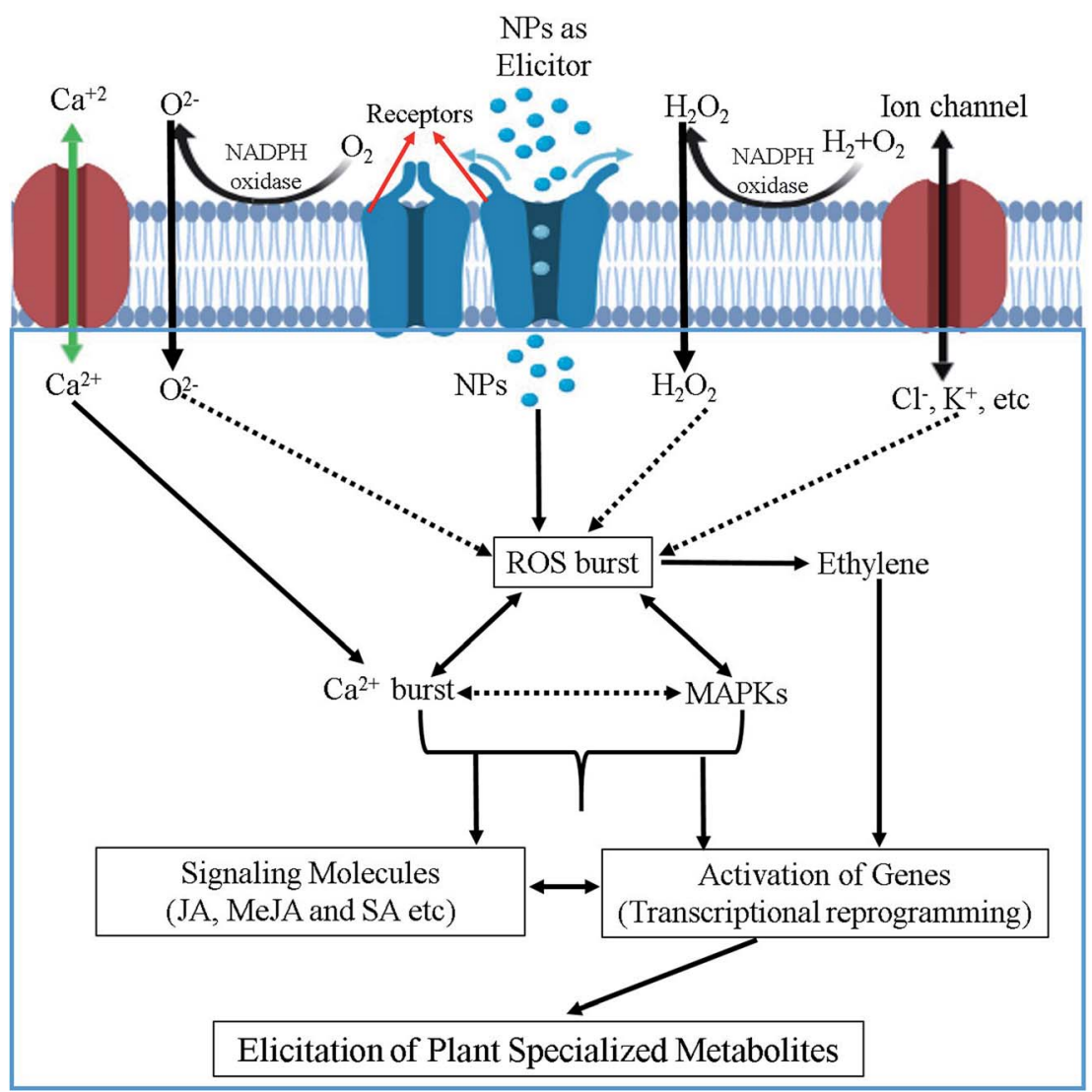

Fig. 4 Schematic illustration of the possible mechanism involved in NPs-mediated elicitation of specialized metabolites in plants.

implied in the elicitation process of plant SMs production. NADPH oxidase and other related oxidases, sometime activated through differential $\mathrm{Ca}^{2+}$ movements, are responsible for generation of ROS in plant cells. ${ }^{14-116}$ This oxidative burst in plant cell can result in the activation of cGMP-dependent protein kinase. These activated protein kinases cause the phosphorylation of mitogen-activated protein kinases (MAPKs), which in turn results in gene expression modulation events. All these transcriptional reprogramming events can further activate the pathways of SMs production in plant cells. ${ }^{117}$ G-proteins (aka guanine nucleotide-binding proteins) can also activate the SMs accumulation indirectly through the de novo biosynthesis of stress signaling compounds such as salicyclic acid (SA), jasmonic acid (JA) and methyl jasmonic acid (MeJA), facilitating plant defense response through the reprogramming of plant specialized metabolism pathways (Fig. 4). ${ }^{118}$

\section{Negative impact of nanomaterials to plant cells and their metabolism}

Despite of numerous advantages, nanomaterials present also some adverse effects on plant physiology, biochemistry, primary and specialized metabolism under certain conditions. All the notorious effects caused by nanomaterials to plant come under the heading of phytotoxicity. Phytotoxicity of nanomaterials depends on a broad range of factors including the type, age, growth medium and growing conditions of the considered plant species along with the nature, exposure time and physicochemical characteristics of nanomaterials used. The exact mechanism of phytotoxicity of nanomaterials is still unclear, but many hypotheses have been proposed. The detailed of proposed phytotoxicity mechanism of nanomaterials is illustrated in Fig. 5. Most commonly proposed mechanism of phytotoxicity of nanomaterials is related with the induced oxidative burst and the generation of ROS, which play a critical role in determining the nature and the type of phytotoxicity. ${ }^{21,119,120}$ ROS can cause oxidative stress, which emerges when the ROS level exceeds the defense mechanisms, and is able to damage plant cells by inducing DNA damage, ${ }^{121}$ membrane damage, ${ }^{122}$ protein oxidation, ${ }^{123}$ lipid peroxidation ${ }^{124}$ and/or electrolyte leakage finally leading to cell death. ${ }^{125}$ In the present review we have already discussed both the positive impact of nanomaterials on the production of plant SMs and biomass, but also presented some examples of negative impact of nanomaterials, growth, viability and/or on primary and specialized metabolism in various plant species (in particular see ref. 42, 68 and 69).

Details of available literature on any phytotoxicity caused by NPs is also given in Tables 1,2 and 3.

To summarize the available literature, a consensus exists on the application of high concentration of nanomaterials. ${ }^{20,80,92}$ This was, for example, illustrated by ${ }^{40}$ with plantlets of $C$. 


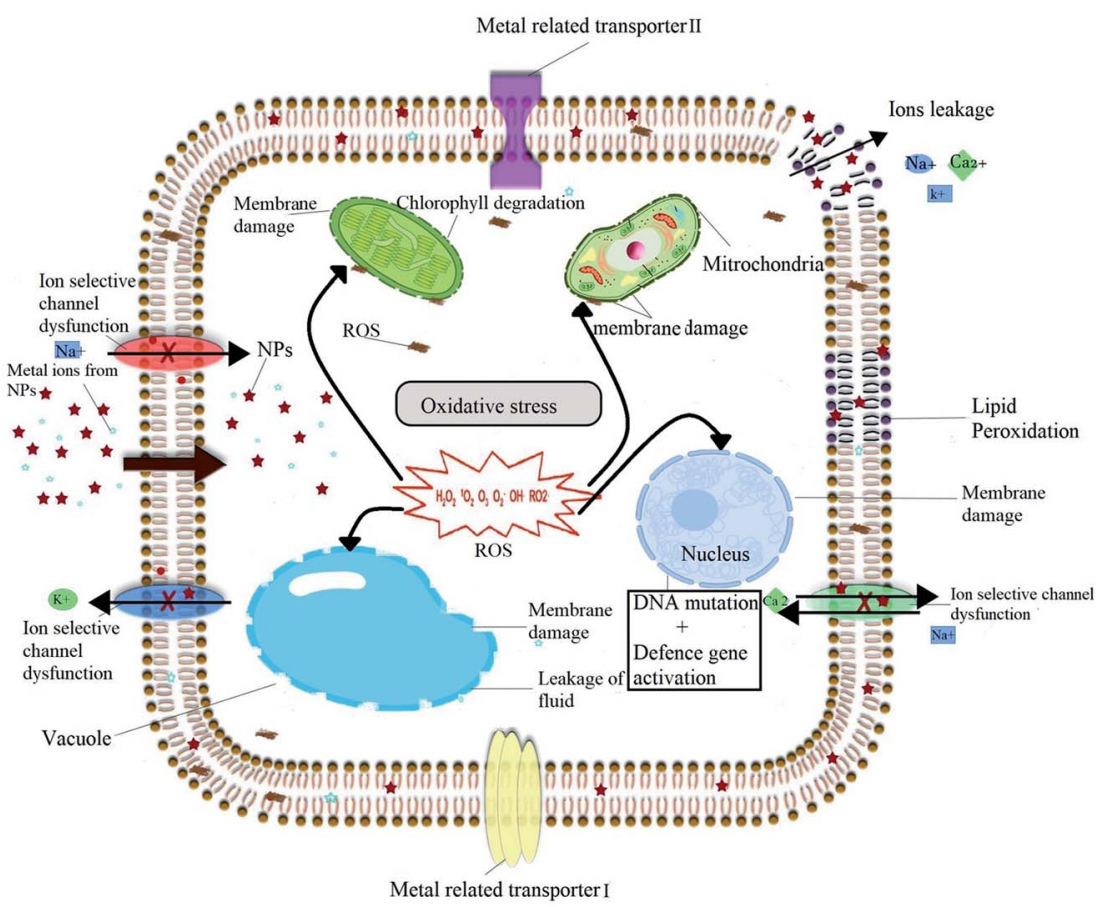

Fig. 5 Diagram showing the possible phytotoxicity induced by the NPs through generation of excessive amount of ROS that could damage nuclear material and cell membranes of various organelles that can eventually lead to cell death.

officinalis exposed to AgNPs at $400 \mathrm{mg} \mathrm{L}^{-1}$. Similarly, phytotoxic effects were observed on seedling of $S$. melongen $a^{80}$ treated with $1000 \mathrm{mg} \mathrm{L}^{-1} \mathrm{CuO}$, ZnO or NiO NPs. Primary metabolism and plant growth can be also affected, as observed with nanozerovalent iron presenting inhibitory effects on the chlorophyll and carotenoid content of rice when used in higher concentration, which in turn decrease the rate of photosynthesis and plant biomass accumulation. ${ }^{126}$ Cell viability could be directly impacted by excessive ROS generation as observed for MWCNTs treated-cell suspension culture of rice. ${ }^{127}$

From the literature review of different studies, it has been evident to us that the smaller size and excess of nanomaterials as well as long exposure time could be harmful for plants and might be a cause of phytotoxicity while used under optimized conditions nanomaterials may be beneficial for plant growth and SMs production. Optimizing these conditions for each plant species and culture system is therefore a prerequisite to investigate carefully when the use of nanomaterials as elicitor of plant SMs production is considered.

\section{Conclusions and future outlooks}

The current review suggests that nanomaterials (MNPs, MONPs and other carbon related nanomaterials) are promising tools to improve the quality and quantity of valuable plant SMs in different culture systems. Among different abiotic elicitors used to date, nanomaterials emerge as efficient elicitors of plant SMs production both in terms of their specificity and productivity. Indeed, enhanced production of a large number of commercially important SMs have been reported in various plant species grown under different culture conditions by using different types of nanomaterials. These results pave the way of a more systematic consideration of nanomaterials as elicitors in plant science.

Overall critical analysis of all reported data on elicitation of plant SMs by nanomaterials showed that the AgNPs and ZnONPs (among all other NPs) proved to be more efficient elicitors both in terms of their productivity and specificity. For production of plant SMs at commercial levels, different researchers reported different optimum concentration of nanomaterials depending on type of culture and plant species used. Most of the published data reported that the lower concentrations of nanomaterials are more efficient in eliciting plant SMs than higher ones, probably due to toxic effects of nanomaterials to plant primary metabolism.

Researches performed on the elicitation of SMs by different types of nanomaterials have demonstrated that the elicitation mechanism is complex and depends on various factors such as the size, morphology, concentration and exposure time of NPs along with the considered plant species and the type of the growing conditions, resulting in different consequences. ${ }^{127-130}$ Paucity of knowledge on the different factors affecting elicitation mechanism by nanomaterials is aggravated by the fact that most of the studies focused on plant growth, development, physiological, including primary metabolism, parameters, but the effect of nanomaterials on plant SMs production is scarcely studied and many questions remain unexplored. For example, an interesting and promising future line of research also includes studying the antagonistic or synergistic effects of one class of nanomaterials on specialized metabolism in 
combination with another class of nanomaterials or with other abiotic/biotic elicitors.

Lack of unanimity exists on the mechanism of elicitation by nanomaterials, as the proposed mechanism may vary according to the plant species, culture conditions and/or type of nanomaterials used. In addition, application routes of the nanomaterials and therefore different mode of exposure, entry and/ or translocation into the plant cells and tissues, internalization could lead to different mode of action. ${ }^{\mathbf{1 0 , 4 1 , 7 2 , 1 0 3 , 1 3 1 , 1 3 2}}$ Plant specialized metabolism includes a wide range of compounds and their biosynthesis are tightly controlled by signaling events. The impact on plant SMs production differs according their phytochemical classes and plant species. A case-by-case analysis of NP type and plant species may be required to better understand the elicitation mechanism. For instance, it would be interesting to consider the accumulation of a particular class of SMs produced in the same plant species grown under in different culture conditions and systems (field or greenhouse $v s$. different in vitro systems). It is, therefore very difficult to propose a general elicitation mechanism for nanomaterials, and their impact on plant SMs production and more studies are required for its comprehensive understanding. Omics-based analyses (e.g. genomics, transcriptomics, proteomics and metabolomics) have to be more systematically considered in order to identify the molecular mechanisms of plant SMs elicitation resulting from nanomaterials applications.

The open challenges for biotechnologists and nanotechnologists to continue their research in this area are: to determine the critical quantities of nanomaterials that plants can safely absorb without showing any signs of phytotoxicity and to understand the mechanistic interactions between the nanomaterials and the plant cells and their SMs pathways. In particular, further researches focusing on the comprehensive identification of the cellular and molecular events responsible for the observed phytotoxic effects of nanomaterials are strongly needed to take a full advantage of the stimulation capacities of these new classes of elicitors on plant SMs production prior to future applications.

Moreover, till now only a few types of nanomaterials are explored as potent elicitors of plant SMs (Ag, $\mathrm{Au}, \mathrm{Zn}, \mathrm{ZnO}, \mathrm{Cu}$, $\mathrm{CuO}, \mathrm{CdO}, \mathrm{Al}_{2} \mathrm{O}_{3}, \mathrm{CeO}_{2}, \mathrm{SiO}_{2}, \mathrm{Ni}$ and $\mathrm{MgO}$ ) whereas, the role of a large number of nanomaterials $\left(\mathrm{Fe}_{2} \mathrm{O}_{3}, \mathrm{Co}, \mathrm{CoO}, \mathrm{NiO}, \mathrm{Nd}_{2} \mathrm{O}_{3}\right.$, fullerene, fullerols, graphene, GO and carbon dots) remain unexplored. These nanomaterials can also act as novel elicitors of plant SMs, and further research should be carried out to find out their possible role in elicitation of valuable secondary metabolites of plants.

\section{Funding source}

This research did not receive any specific grant from funding agencies in the public, commercial, or not-for-profit sectors.

\section{Conflicts of interest}

There are no conflicts to declare.

\section{References}

1 P. N. Sudha, K. Sangeetha, K. Vijayalakshmi and A. Barhoum, in Emerging Applications of Nanoparticles and Architecture Nanostructures, Elsevier, 2018, pp. 341-384.

2 F. Ye, Y. Zhao, R. El-Sayed, M. Muhammed and M. Hassan, Nano Today, 2018, 18, 103-123.

3 Y. Xia, Angew. Chem., Int. Ed., 2014, 53, 12265.

4 V. F. Cardoso, A. Francesko, C. Ribeiro, M. Bañobre-López, P. Martins and S. Lanceros-Mendez, Adv. Healthcare Mater., 2018, 7, 1700845.

5 D. Kim, K. Shin, S. G. Kwon and T. Hyeon, Adv. Mater., 2018, 30, 1802309.

6 H. Chhipa, Environ. Chem. Lett., 2017, 15, 15-22.

7 J. S. Duhan, R. Kumar, N. Kumar, P. Kaur, K. Nehra and S. Duhan, Biotechnology Reports, 2017, 15, 11-23.

8 A. Servin, W. Elmer, A. Mukherjee, R. De la Torre-Roche, H. Hamdi, J. C. White, P. Bindraban and C. Dimkpa, J. Nanopart. Res., 2015, 17, 92.

9 H. Feizi, S. Amirmoradi, F. Abdollahi and S. J. Pour, Annu. Res. Rev. Biol., 2013, 814-824.

10 M. Hatami, K. Kariman and M. Ghorbanpour, Sci. Total Environ., 2016, 571, 275-291.

11 G. Marslin, C. J. Sheeba and G. Franklin, Frontiers in Plant Science, 2017, 8, 832-844.

12 S. Baikar and N. Malpathak, Pharmacogn. Rev., 2010, 4, 1221.

13 M. Greenwell and P. Rahman, Int. J. Pharm. Sci. Res., 2015, 6, 4103.

14 A. Seca and D. Pinto, Int. J. Mol. Sci., 2018, 19, 263.

15 M. Ali, B. H. Abbasi, N. Ahmad, H. Khan and G. S. Ali, Crit. Rev. Biotechnol., 2017, 37, 833-851.

16 C. C. Giri and M. Zaheer, Plant Cell, Tissue Organ Cult., 2016, 126, 1-18.

17 M. S. Hussain, S. Fareed, M. Saba Ansari, A. Rahman, I. Z. Ahmad and M. Saeed, J. Pharm. BioAllied Sci., 2012, 4, 10-24.

18 K. R. Asl, B. Hosseini, A. Sharafi and J. Palazon, Eng. Life Sci., 2019, 19, 73-89.

19 P. Bhat and A. Bhat, J. Exp. Sci., 2016, 1-6.

20 F. Moharrami, B. Hosseini, A. Sharafi and M. Farjaminezhad, In Vitro Cell. Dev. Biol.: Plant, 2017, 53, 104-111.

21 C. Ma, J. C. White, O. P. Dhankher and B. Xing, Environ. Sci. Technol., 2015, 49, 7109-7122.

22 L. Marchiol, A. Mattiello, F. Pošćić, C. Giordano and R. Musetti, Nanoscale Res. Lett., 2014, 9, 101.

23 P. Wang, E. Lombi, F.-J. Zhao and P. M. Kopittke, Trends Plant Sci., 2016, 21, 699-712.

24 F. Aslani, S. Bagheri, N. Muhd Julkapli, A. S. Juraimi, F. S. G. Hashemi and A. Baghdadi, Sci. World J., 2014, 2014, 1-29.

25 R. Nair, S. H. Varghese, B. G. Nair, T. Maekawa, Y. Yoshida and D. S. Kumar, Plant Sci., 2010, 179, 154-163. 
26 M. S. Riaza, N. Ullaha, H. Alid and A. Nadhmane, Analysis, Fate, and Toxicity of Engineered Nanomaterials in Plants, 2019, vol. 84, p. 23.

27 Y.-q. Deng, J. C. White and B.-s. Xing, J. Zhejiang Univ., Sci., $A, 2014,15,552-572$.

28 I.-M. Chung, K. Rekha, G. Rajakumar and M. Thiruvengadam, 3 Biotech, 2018, 8, 412.

29 I.-M. Chung, K. Rekha, G. Rajakumar and M. Thiruvengadam, Bioprocess Biosyst. Eng., 2018, 41, 1665-1677.

30 P. Golkar, M. Moradi and G. A. Garousi, Sugar Tech, 2018, 19.

31 I.-M. Chung, G. Rajakumar and M. Thiruvengadam, Acta Biol. Hung., 2018, 69, 97-109.

32 S. D. Gupta, A. Agarwal and S. Pradhan, Ecotoxicol. Environ. Saf., 2018, 161, 624-633.

33 J. Yasur and P. U. Rani, Environ. Sci. Pollut. Res., 2013, 20, 8636-8648.

34 A. Zahir, M. Nadeem, W. Ahmad, N. Giglioli-Guivarc'h, C. Hano and B. H. Abbasi, Plant Cell, Tissue Organ Cult., 2019, 136, 589-596.

35 M. Raei, S. A. Angaji, M. Omidi and M. Khodayari, Int. J. Biosci., 2014, 5, 74-81.

36 Z. Shakeran, M. Keyhanfar, G. Asghari and M. Ghanadian, Turk. J. Biol., 2015, 39, 111-118.

37 B. Zhang, L. P. Zheng, W. Yi Li and J. Wen Wang, Curr. Nanosci., 2013, 9, 363-370.

38 B. Ghasemi, R. Hosseini and F. D. Nayeri, Turk. J. Bot., 2015, 39, 769-777.

39 F. Tahoori, M. Ahmad, T. Nejadsattari, H. Ofoghi and A. Iranbakhsh, Not. Bot. Horti Agrobot. Cluj-Napoca, 2019, 47, 143-151.

40 F. Ghanati and S. Bakhtiarian, Trop. J. Pharm. Res., 2014, 13, 1783-1789.

41 M. Jamshidi and F. Ghanati, Plant Physiol. Biochem., 2017, 110, 178-184.

42 M. Jamshidi, F. Ghanati, A. Rezaei and E. Bemani, Cytotechnology, 2016, 68, 525-530.

43 Z. Aghajani and R. Ekhtiyari, Afr. J. Agric. Res., 2013, 8, 707710.

44 M. Abbasi Khalaki, A. Ghorbani and M. Moameri, Journal of Rangeland Science, 2016, 6, 221-231.

45 L. Azeez, A. Lateef and S. A. Adebisi, Appl. Nanosci., 2017, 7, 59-66.

46 B. Jasim, R. Thomas, J. Mathew and E. Radhakrishnan, Saudi Pharm. J., 2017, 25, 443-447.

47 Y.-y. Syu, J.-H. Hung, J.-C. Chen and H.-w. Chuang, Plant Physiol. Biochem., 2014, 83, 57-64.

48 J. Spinoso-Castillo, R. Chavez-Santoscoy, N. Bogdanchikova, J. Pérez-Sato, V. Morales-Ramos and J. Bello-Bello, Plant Cell, Tissue Organ Cult., 2017, 129, 195-207.

49 S. García-Sánchez, I. Bernales and S. Cristobal, BMC Genomics, 2015, 16, 341.

50 P. Logeswari, S. Silambarasan and J. Abraham, J. Saudi Chem. Soc., 2015, 19, 311-317.
51 A. Ali, S. Mohammad, M. A. Khan, N. I. Raja, M. Arif, A. Kamil and Z.-u.-R. Mashwani, Artif. Cells, Nanomed., Biotechnol., 2019, 47, 715-724.

52 P. Golkar, M. Moradi and G. A. Garousi, Sugar Tech, 2019, 21, 569-577.

53 C. Krishnaraj, E. Jagan, R. Ramachandran, S. Abirami, N. Mohan and P. Kalaichelvan, Process Biochem., 2012, 47, 651-658.

54 E. A. Genady, E. A. Qaid and A. H. Fahmy, Int. J. Pharm. Res. Allied Sci., 2016, 5, 196-202.

55 E. López-Vargas, H. Ortega-Ortíz, G. Cadenas-Pliego, K. de Alba Romenus, M. Cabrera de la Fuente, A. BenavidesMendoza and A. Juárez-Maldonado, Appl. Sci., 2018, 8, 1020. 56 T. Talankova-Sereda, K. Liapina, E. Shkopinskij, A. Ustinov, A. Kovalyova, P. Dulnev and N. Kucenko, in Nanophysics, Nanophotonics, Surface Studies, and Applications, Springer, 2016, pp. 427-436.

57 L. Zhao, Y. Huang, J. Hu, H. Zhou, A. S. Adeleye and A. A. Keller, Environ. Sci. Technol., 2016, 50, 2000-2010.

58 H. Fazal, B. H. Abbasi, N. Ahmad and M. Ali, Appl. Biochem. Biotechnol., 2016, 180, 1076-1092.

59 B. Ghazal, S. Saif, K. Farid, A. Khan, S. Rehman, A. Reshma, H. Fazal, M. Ali, A. Ahmad and L. Rahman, IET Nanobiotechnol., 2018, 12, 569-573.

60 R. Singh, D. P. Singh, P. Gupta, P. Jain, T. Mishra, A. Kumar, S. S. Dhawan and P. A. Shirke, Ind. Crops Prod., 2019, 127, 94-109.

61 H. Fazal, B. H. Abbasi, N. Ahmad, M. Ali, S. Shujait Ali, A. Khan and D.-Q. Wei, Artif. Cells, Nanomed., Biotechnol., 2019, 47, 2553-2561.

62 A. Wesołowska, P. Jadczak, D. Kulpa and W. Przewodowski, Molecules, 2019, 24, 606.

63 I.-M. Chung, K. Rekha, B. Venkidasamy and M. Thiruvengadam, Water, Air, Soil Pollut., 2019, 230, 48-62.

64 I.-M. Chung and M. Thiruvengadam, Appl. Sci., 2019, 9, 213-223.

65 M. A. Khan, T. Khan, M. S. Riaz, N. Ullah, H. Ali and A. Nadhman, Adv. Colloid Interface Sci., 2019, 272, 431-446.

66 N. Zuverza-Mena, D. Martinez-Fernandez, W. Du, J. A. Hernandez-Viezcas, N. Bonilla-Bird, M. L. LopezMoreno, M. Komarek, J. R. Peralta-Videa and J. L. GardeaTorresdey, Plant Physiol. Biochem., 2017, 110, 236-264.

67 V. Rajput, T. Minkina, S. Suskova, S. Mandzhieva, V. Tsitsuashvili, V. Chapligin and A. Fedorenko, J. Bionanosci., 2018, 8, 36-42.

68 I. Yruela, Braz. J. Plant Physiol., 2005, 17, 145-156.

69 N. ul Ain, I. ul Haq, B. H. Abbasi, R. Javed and M. Zia, IET Nanobiotechnol., 2017, 12, 349-356.

70 O. S. Singh, N. C. Pant, M. Laishram, R. D. Tewari, K. Joshi and C. Pandey, J. Pharmacogn. Phytochem., 2018, 7, 34333439.

71 I.-M. Chung, K. Rekha, G. Rajakumar and M. Thiruvengadam, 3 Biotech, 2016, 6, 175.

72 L. Laishram, N. C. Pant, O. S. Singh, R. Dhoundiyal, K. Joshi and C. Pandey, Int. J. Conserv. Sci., 2018, 6, 3270-3276. 
73 E. Chamani, S. Karimi Ghalehtaki, M. Mohebodini and A. Ghanbari, Iranian Journal of Genetics and Plant Breeding, 2015, 4, 11-19.

74 A. Kołodziejczak-Radzimska and T. Jesionowski, Materials, 2014, 7, 2833-2881.

75 H. Oloumi, R. Soltaninejad and A. Baghizadeh, Indian J. Plant Physiol., 2015, 20, 157-161.

76 N. Karimi, M. Behbahani, G. Dini and A. Razmjou, Adv. Nat. Sci.: Nanosci. Nanotechnol., 2018, 9, 045009.

77 P. Raigond, B. Raigond, B. Kaundal, B. Singh, A. Joshi and S. Dutt, J. Environ. Biol., 2017, 38, 435.

78 R. Javed, M. Usman, B. Yücesan, M. Zia and E. Gürel, Plant Physiol. Biochem., 2017, 110, 94-99.

79 R. Javed, B. Yucesan, M. Zia and E. Gurel, Sugar Tech, 2018, 20, 194-201.

80 V. Baskar, S. Nayeem, S. P. Kuppuraj, T. Muthu and S. Ramalingam, 3 Biotech, 2018, 8, 362.

81 T. E. S. Ahamed, J. Plant Sci., 2018, 6, 157.

82 M. Mohebodini, R. Fathi and N. Mehri, Iranian Journal of Genetics and Plant Breeding, 2017, 6, 60-68.

83 E. Sharafi, S. Khayam Nekoei, M. H. Fotokian, D. Davoodi, H. Hadavand Mirzaei and T. Hasanloo, Journal for the Measurement of Physical Behaviour, 2013, 2, 177-184.

84 P. Shakya, G. Marslin, K. Siram, L. Beerhues and G. Franklin, J. Pharm. Pharmacol., 2019, 71, 70-82.

85 J. Wang, J. Qian, L. Yao and Y. Lu, Bioresources and Bioprocessing, 2015, 2, 5.

86 A. A. Keller, S. McFerran, A. Lazareva and S. Suh, J. Nanopart. Res., 2013, 15, 1692.

87 L. V. Antisari, S. Carbone, A. Gatti, G. Vianello and P. Nannipieri, Environ. Sci. Pollut. Res., 2015, 22, 1841-1853.

88 Z. Lei, S. Mingyu, W. Xiao, L. Chao, Q. Chunxiang, C. Liang, H. Hao, L. Xiaoqing and H. Fashui, Biol. Trace Elem. Res., 2008, 121, 69-79.

89 H. K. M. AL-oubaidi and N. M. Kasid, World J. Pharm. Res., 2015, 4, 1791-1799.

90 M. Ghorbanpour, Indian J. Plant Physiol., 2015, 20, 249-256.

91 M. Ghorbanpour, M. Hatami and M. Hatami, Acta Agric. Slov., 2015, 105, 23-32.

92 M. Kamalizadeh, M. Bihamta and A. Zarei, Acta Physiol. Plant., 2019, 41, 21.

93 Y. Rui, P. Zhang, Y. Zhang, Y. Ma, X. He, X. Gui, Y. Li, J. Zhang, L. Zheng and S. Chu, Environ. Pollut., 2015, 198, 8-14.

94 F. Schwabe, S. Tanner, R. Schulin, A. Rotzetter, W. Stark, A. Von Quadt and B. Nowack, Metallomics, 2015, 7, 466-477.

95 B. Corral-Diaz, J. R. Peralta-Videa, E. Alvarez-Parrilla, J. Rodrigo-García, M. I. Morales, P. Osuna-Avila, G. Niu, J. A. Hernandez-Viezcas and J. L. Gardea-Torresdey, Plant Physiol. Biochem., 2014, 84, 277-285.

96 I. Hussain, N. Singh, A. Singh, H. Singh, S. Singh and V. Yadav, Sci. Hortic., 2017, 214, 158-164.

97 B. C. Nelson, S. H. Coskun, C. Ma, H. Li, H. Guo, C. Musante, J. C. White, B. Xing and O. P. Dhankher, Environ. Sci.: Nano, 2016, 3, 1369-1379.

98 Z. Poborilova, R. Opatrilova and P. Babula, Environ. Exp. Bot., 2013, 91, 1-11.
99 A. Pompeiano, J. T. Ãska, M. Oravec and O. Urban, Environmental pollution, 2016.

100 H. Tian, M. Ghorbanpour and K. Kariman, Ind. Crops Prod., 2018, 126, 403-414.

101 E. Nourozi, B. Hosseini, R. Maleki and B. A. Mandoulakani, Ind. Crops Prod., 2019, 133, 435-446.

102 M. M. H. Kahila, A. M. Najy, M. Rahaie and M. MirDerikvand, Nat. Prod. Res., 2018, 32, 1858-1862.

103 A. Husen and K. S. Siddiqi, J. Nanobiotechnol., 2014, 12, 16.

104 X. Ma, J. Geiser-Lee, Y. Deng and A. Kolmakov, Sci. Total Environ., 2010, 408, 3053-3061.

105 S. Lin, J. Reppert, Q. Hu, J. S. Hudson, M. L. Reid, T. A. Ratnikova, A. M. Rao, H. Luo and P. C. Ke, Small, 2009, 5, 1128-1132.

106 P. Miralles, E. Johnson, T. L. Church and A. T. Harris, J. $R$. Soc., Interface, 2012, 9, 3514-3527.

107 S. Ahmadi, M. Ghorbanpour, J. Hadian and H. SalehiArjmand, Journal of Medicinal Plants, 2018, 4, 82-98.

108 A. A. Gaafar, R. A. Taha, N. H. Abou-Baker, E. A. Shaaban and Z. A. Salama, Biosci. Res., 2018, 15, 2383-2392.

109 M. Ghorbanpour and J. Hadian, Carbon, 2015, 94, 749-759.

110 C. Kole, P. Kole, K. M. Randunu, P. Choudhary, R. Podila, P. C. Ke, A. M. Rao and R. K. Marcus, BMC Biotechnol., 2013, 13, 37.

111 S. Chandra, N. Chakraborty, A. Dasgupta, J. Sarkar, K. Panda and K. Acharya, Sci. Rep., 2015, 5, 15195.

112 A. Sosan, D. Svistunenko, D. Straltsova, K. Tsiurkina, I. Smolich, T. Lawson, S. Subramaniam, V. Golovko, D. Anderson and A. Sokolik, Plant J., 2016, 85, 245-257.

113 G. P. Bolwell and P. Wojtaszek, Physiol. Mol. Plant Pathol., 1997, 51, 347-366.

114 R. Berni, M. Luyckx, X. Xu, S. Legay, K. Sergeant, J.-F. Hausman, S. Lutts, G. Cai and G. Guerriero, Environ. Exp. Bot., 2018, 9, 413-423.

115 M. N. Khan, M. Mobin, Z. K. Abbas, K. A. AlMutairi and Z. H. Siddiqui, Plant Physiol. Biochem., 2017, 110, 194-209.

116 J. Zhao, Q. Hu, Y.-Q. Guo and W.-H. Zhu, Plant Sci., 2001, 161, 423-431.

117 U. J. Phukan, G. S. Jeena and R. K. Shukla, Frontiers in Plant Science, 2016, 7, 760.

118 E. Kohan-Baghkheirati and J. Geisler-Lee, Nanomaterials, 2015, 5, 436-467.

119 M. Kumari, S. S. Khan, S. Pakrashi, A. Mukherjee and N. Chandrasekaran, J. Hazard. Mater., 2011, 190, 613-621.

120 C. Ma, Y. Rui, S. Liu, X. Li, B. Xing and L. Liu, Sci. Rep., 2015, 5, 11618.

121 P. Sharma, A. B. Jha, R. S. Dubey and M. Pessarakli, J. Bot., 2012, 2012, 1-26.

122 J.-L. Montillet, S. Chamnongpol, C. Rustérucci, J. Dat, B. Van De Cotte, J.-P. Agnel, C. Battesti, D. Inzé, F. Van Breusegem and C. Triantaphylides, Plant Physiol., 2005, 138, 1516-1526.

123 I. M. Møller and B. K. Kristensen, Photochem. Photobiol. Sci., 2004, 3, 730-735.

124 C. O. Dimkpa, J. E. McLean, D. E. Latta, E. Manangón, D. W. Britt, W. P. Johnson, M. I. Boyanov and A. J. Anderson, J. Nanopart. Res., 2012, 14, 1125. 
125 P. Zhang, Y. Ma, Z. Zhang, X. He, Y. Li, J. Zhang, L. Zheng and Y. Zhao, Nanotoxicology, 2015, 9, 1-8.

126 A. Montes, M. A. Bisson, J. A. Gardella Jr and D. S. Aga, Sci. Total Environ., 2017, 607, 1497-1516.

127 P. Dey and N. Das, Int. J. Pharm. Pharm. Sci., 2013, 5, 9-13. 128 E. V. Basiuk, O. E. Ochoa-Olmos and L. F. De la MoraEstrada, J. Nanosci. Nanotechnol., 2011, 11, 3016-3038.
129 W. Bao, J. Wang, Q. Wang, D. Hare and Y. Wan, Sci. Rep., 2015, 6, 26738-26747.

130 S. K. Verma, A. K. Das, M. K. Patel, A. Shah, V. Kumar and S. Gantait, Sci. Total Environ., 2018, 630, 1413-1435.

131 D. H. Kim, J. Gopal and I. Sivanesan, RSC Adv., 2017, 7, 36492-36505.

132 W. M. Lee, Y. J. An, H. Yoon and H. S. Kweon, Environ. Toxicol. Chem., 2008, 27, 1915-1921. 